\title{
Future smart energy software houses
}

\author{
Petri Kettunen ${ }^{*}$ (D) and Niko Mäkitalo
}

\begin{abstract}
Software is the key enabling technology (KET) as digitalization is cross-cutting future energy systems spanning the production sites, distribution networks, and consumers particularly in electricity smart grids. In this paper, we identify systematically what particular software competencies are required in the future energy systems focusing on electricity system smart grids. The realizations of that can then be roadmapped to specific software capabilities of the different future 'software houses' across the networks. Our instrumental method is software competence development scenario path construction with environmental scanning of the related systems elements. The vision of future software-enabled smart energy systems with software houses is mapped with the already progressing scenarios of energy systems transitions on the one hand coupled with the technology foresight of software on the other hand. Grounding on the Smart Grid Reference Architecture Model (SGAM), it tabulates the distinguished software competencies and attributes them to the different parties-including customers/consumers (Internet of People, loP)_involved in future smart energy systems. The resulting designations can then be used to recognize and measure the necessary software competencies (e.g., fog computing) in order to be able to develop them inhouse, or for instance to partner with software companies, depending on the future desirability. Software-intensive systems development competence becomes one of the key success factors for such cyber-physical-social systems (CPSS). Further futures research work is chartered with the Futures Map frame. This paper contributes preliminarily toward that by identifying pictures of the software-enabled futures and the connecting software competencebased scenario paths.
\end{abstract}

Keywords: Digital transformation, Smart grid, Software competence, Systems thinking, Cyber-physical-social systems, Futures map

\section{Introduction}

Energy systems are in global transition. Software is the key enabling technology (KET) as digitalization is cross-cutting future energy systems spanning the production sites, distribution networks, and consumers particularly in electricity smart grids. It follows that there will be more and more "software houses" in the future smart energy systems [1]. In all, the role of software increases across the future energy systems and, consequently, new and improved software competencies are needed to develop and utilize systems software, applications, data, and communications across the energy networks. Consequently, there are major needs for new and improved software capabilities in different organizations across the entire networks.

Our overarching futures research approach is inspired by the Futures Map frame [2]. The crucial research notions and concepts in this paper derive from that. The

\footnotetext{
* Correspondence: petri.kettunen@cs.helsinki.fi

Department of Computer Science, University of Helsinki, Helsinki, Finland
}

vision of future software-enabled smart energy systems with software houses is aligned with the already progressing scenario paths of energy systems transitions (particularly smart grids) on the one hand coupled with the technology roadmaps of software on the other hand. In addition, we recognize the changing consumer behaviors and expectations (e.g., digital services, sustainability) acting as drivers to our software focus. Our working time horizon is the year 2030 which is typically used in many current energy systems studies and policies (e.g., EU).

The research strategy of this paper is dualistic. First, we identify systematically what particular software competencies are required in the future energy systems (focusing on smart grids). Based on that holistic understanding, we determine by inference what the consequent impacts for (incumbent) non-software organizations are, and compile possible scenario paths how they can advance toward becoming proficient at software. The realizations of that can then be mapped 
to specific software capabilities of the different future "software houses" across the networks (e.g., distribution system operators (DSO)).

The direct contribution of this paper is a software key competence assessment and development scheme. Grounding on the Smart Grid Reference Architecture Model (SGAM) [3], it tabulates the distinguished software competencies and maps them to the different parties-including customers/consumers (Internet of People, IoP)-involved in future smart energy systems. The resulting mapping can then be used to recognize and measure the necessary software competencies (e.g., fog computing) in order to be able to develop them in-house, or for instance to partner with software companies. Consequently, each organization can then create and improve the key organizational capabilities to be competitive in the pictures of future software-intensive energy system value networks depending on their scenario paths.

Overall, digital transformations of energy systems are enabled by software. This is particularly so in electricity systems smart grids in which more and more digital elements (ICT) are incorporated in all layers of the networks and across the actors. In the smart grid context, this leads to future software development and application roadmap levels ranging from smart components (e.g., next-generation automated meter reading (AMR)) to digital service businesses. Software-intensive systems development competence becomes one of the key success factors for such cyber-physical-social systems (CPSS). On the other hand, lack of the new software-related competencies and organizational capabilities may slow down future energy system transitions and may cause new risks for sustainability (e.g., cyber-security). Like we present in this paper, by systematically recognizing such needs, opportunities and also undesirable pictures of futures, it will be possible to build intelligently future large-scale smart and sustainable energy systems with software. This is where interdisciplinary futures research can be foundational for both energy systems R\&D\&I and software research. Our contribution here is in suggesting what certain advanced computer science knowledge and modern software technology development can provide for desired pictures of futures and their related scenario paths.

The rest of this paper is organized as follows. The next section frames the overall landscape of future energy systems and software focusing on electricity systems. Based on that holistic comprehension, the following section takes the core computer science perspective of software systems and data in electricity systems smart grids. That is continued by particularized identification of software-related dependencies on the one hand and certain new software-enabled opportunities on the other hand. The succeeding section then presents our scheme of distinguishing the particular software competencies and capabilities. Finally, we conclude with discussion and conclusions of implications and pointers for further futures research work with the Futures Map approach.

\section{Future energy systems and software}

Energy systems are undergoing global transitions. This is in particular the case with electricity power systems which are currently developed toward smart grids. The traditional grids evolve to accommodate new requirements and to integrate new technologies, in particular modern ICT [3]. This can provide extended application and management capabilities across increasingly integrated networks. On the other hand, new network dynamics will require more flexible, "smarter" approach for the management of distributed electricity supply and demand. Advanced ICT infrastructure and solutions become key enabling components. Software-related futures can be recognized in all.

\section{Energy sector drivers, opportunities, and challenges}

Currently, there are many major, even global factors affecting energy systems development. While most of that is beyond the scope of our work, it is nevertheless essential to recognize them at a high level in order to be able to understand the role of software and to position the software research in that context.

To begin with, there is an ongoing transition to low-carbon energy systems [4]. Such transitions in electricity depend not only on innovations in the primary energy technologies but also on complementary innovations in electricity networks such as smart grids [5]. In total, developing smart and flexible energy systems requires combining technical, economic, meteorological, and computer science (CS) expertise and new investments to ICT-based solutions [6]. Widespread electrification may significantly shape energy-system infrastructures development, and road maps can be directed also to enabling technologies such as ICT $[7,8]$.

One of the main development trends is the changing role of customers and end-users. In the future, they are expected to become prosumers both consuming and producing electricity with for instance their building solar panels [8]. Such development leads to even massive distribution of the energy resources (distributed energy resource (DER)) in the grid with new dynamics of two-way energy flows. While that increases the flexibility of the energy system, it also bring new requirements for controlling the grid in particular to balance the overall production and consumption with intermittent energy sources and storage coupled with the industrial sites and controllable power generation. In effect, the traditional operation and business model of utilities is changing 
from one-way electricity providers toward democratizing the power grid [9].

Considering the above current and expected future developments, the entire energy industry is facing even disruptive changes. The role of digitalization in these transitions and transformations ranges from incremental ones (e.g., increasing automation) to even radical structural reconfigurations by for instance digital platform economy [10]. Notably, the electricity technology industry can be seen to encompass not only the equipment manufacturers but also software companies developing smart grid technologies as well as service providers [11]. Aligning with that line of thinking for example the ENTSO-E roadmap comprises such areas as power system modernization, power system economics and efficiency, and ICT and digitalization of power systems [12].

All those change factors in the energy sector introduce needs for new skills and competencies. These concerns are already reflected in various curricula by many related educational programs and institutes. For instance, the current topics in electric power systems engineering may address solving complex power system problems in multidisciplinary ways and awareness of emerging technology issues facing the energy business [13]. The education of the future power sector workforce includes in particular many aspects of smart grids such as data management, and interoperability [14]. The growing importance of ICT should be taken into account to prepare present workforce for future smart grids [15]. Moreover, the structural transformation in the electricity industry leads to job changes in the transformation to a services economy that requires a different skill set since future power systems jobs will involve more about software and services, platforms, interconnections, and system optimization of the increasingly complex systems [16]. Suggested curriculum items for the Internet of Things (IoT)-like future smart energy systems-include architectures and organization, intelligent systems, networking and communications, platform-based development, systems fundamentals, and-notably-also social issues [17].

By and large future energy systems-particularly electricity systems-are complex technological, social, economic, and environmental constellations [7, 18]. It follows that in addition to the specific discipline, knowledge also high-level competencies like complex systems thinking and modeling are increasingly needed to understand new electricity systems with smart grids [19]. There are different subsystems which coevolve and influence each other like new technology and consumer behavior [20].

Overall, acquiring and developing such new skills and competencies may be a considerable challenge for DSOs and they are currently investing in R\&D and demonstration projects in cooperation with the ICT industry to get the knowledge and skills needed [21]. Many of them (if not all) involve some software competencies. Interestingly, software and ICT-related competencies are also specific new requirements in recent job recruitment descriptions of many electricity and utility companies.

\section{Important software-related paths, pictures, and relevant present facts}

Considering that future energy systems and the smart grids build on system-wide intelligence with a multitude of data sources and two-way interconnections, the software-related futures will be chartered by various new ICT solutions in those systems. System architecture design and system properties (e.g., security) become principal means.

On the whole, the key objectives of electricity system smart grids are to support new types of energy markets with digital interactive customer interfaces, active energy resources, demand response, and comprehensive ICT solutions, and to ensure the operation of the critical electricity infrastructure with for example fault management, disturbance management, self-healing networks, and island operation [22]. Such new functionalities are fundamentally software-based. Software (IT) and communication systems are enabling conditions for smart grid development and the more advanced technologies like AMR and remote controlled grid elements are supported by the digital ICT infrastructure.

Smart grids can be conceptualized as intelligent networks with digital processing and communication enabling continuous data flow and information management control to the power grid [23]. They incorporate various smart components. With the inclusion of such new technology as distributed DERs, there become necessities of smart operations. Such new operations are increasingly software-based solutions (e.g., advanced metering infrastructure (AMI) as a backbone of real-time data exchange). Smart components also introduce new software-related dependencies, such as smart device storage and security requirements. In addition, notably, also various grid planning and problem solution tools are software solutions (algorithms).

Accordingly, the current main perspectives on the future of electric distribution focus on active distribution system management and smart metering and data management [21]. Smart meters are considered as key tools for the deployment of smart grids, and the data streams must be managed in cost-efficient and secure ways.

The development of the traditional centralized energy systems toward more decentralized ones also creates new software-related features and properties of electricity system smart grids. In particular, future software system architectures will have to support 
both centralized and decentralized concepts [3]. Flexibility in demand and supply depends ultimately on "smart customers" and their dynamic cooperative interactions. Accordingly, for instance the European Electricity Grid Initiative (EEGI) conceives the following developmental levels [21]:

- Level 5: Smart customers

- Level 4: Smart energy management

- Level 3: Smart integration

- Level 2: Smart distribution network and processes

- Level 1: Smart Pan-European transmission network

- Level 0: New generation technologies

Digitalization is also one influencing factor of the grid edge transformation [8]. Smart devices are key enablers there. The data from them becomes increasingly important as the value chains become more widely digitalized and information is shared. The key technologies both in the networks (smart metering, remote control, and automation systems) and beyond the meter (platforms, smart appliances, and devices) incorporate software.

Overall, data-and furthermore the information derived from data-can be expected to become a critical assets for the smart energy transition [24]. That comprises in particular the integration of the smart metering data collection system with the distribution management system (DMS). It follows that proper data handling and data management models are needed for interoperability and to cope with the increasing volumes and types of data from new sources.

Following the above line of reasoning, it is constructive to approach software-related futures in energy systems from multiple perspectives. Such plausible views are for instance technology, smart grid implementations, end-user, and electricity market perspectives [22]. Key is then to recognize software from each perspective. For example considering smart grids technologically, software is involved not only in network IT and ICT systems but also in network operations and planning. In the smart grid implementations, automation and advanced equipment (e.g., AMR, advanced relays, remotely controlled grid elements) also incorporate software. Even the end-users will be more coupled with software for instance with their electricity consumption information services [9]. In a similar vein, if we expect such intelligence as automated demand response (DR) systems become more commonplace, there will be software needs to realize for instance the necessary communications between systems [25].

Currently, there is a wide range of different IT solutions in smart grid implementations. There are no universal dominant designs. Many grid equipment manufacturers for example provide their own automation platforms.
Another particular design choice is the grid communication infrastructure which DSOs may build by themselves or use the (public) services provided by telcos [26]. In effect, the ICT infrastructure and ICT solutions become part of the smart grid ecosystem [3]. It follows that software (ICT) companies are new key actors in electricity system realizations and business.

Also, the related applicable software technologies are evolving. One of such key technologies is cloud computing which is already mainstream of IS realizations in many business domains. It is under development how cloud computing could enable large-scale variable distributed energy solutions including marketplace of electricity trading [6].

Finally, although we are focusing on software as the key enabling technology, it is cogent to be aware of the main developments in other key technology and research areas of electricity systems and their potential impacts on smart grids software. Such topics are for instance data transmission by real-time communications, supply and demand side management, dynamic pricing, distributed generation, and network load balance management [27]. While for example the dynamic pricing concerns primarily economics and customer behavior, it also incorporates software to process and distribute the consumption and price information with end-user application interfaces. Considering ICT, one of the major evolving areas under research and development is the smart grid communication technology and infrastructure design [28]. There, the development of the general cellular network technologies (e.g., 5G) and various existing IoT communication technologies are drivers and influencing factors.

From the overall software research theoretical point of view, it is foundational to realize that smart grids are instances of cyber-physical systems (CPS) or seeing even more broadly cyber-physical-social ones (CPSS). A holistic, whole-grid research and development requires bridging systems science and engineering with CS and software engineering addressing the multidisciplinary system requirements and constraints at different levels [29]. Their proficient design requires advanced competencies due to the heterogeneous nature, physical world concurrent processes, and timeliness requirements [30]. Modern energy systems are such, and electricity smart grids are prime examples in practice-the power system being the physical part and the software subsystems making the cyber part. Notably, there are considerable research problems concerning for example multidisciplinary integrated system architecture modeling.

Considering smart grids as CPS(S)es, one of the current key issues is their security. Cyber-security of smart grids is inherently software-related due to its cross-cutting nature. It is thus crucial to disentangle the 
role of software in security threats and vulnerabilities on the one hand, and then be able to resolve them as software design and operation problems on the other hand. There exist guidelines for ensuring that the systems are secure by implementing appropriate protective measures supported by the software and hardware vendors, contractors, IT, and telecommunications service providers [31]. However, smart grid security in total is still in a nascent state and even cyber-physical attacks must seriously be taken into account in the future [32, 33].

Another critical software-related CPS problem area is smart grid system safety. Smart grids are parts of critical national infrastructures and they are also safety-critical systems. Software-related failures could endanger not only monetary interests but even public safety in modern electrified societies. Future systems safety engineering must therefore take software dependencies more comprehensively into account and software engineering must be able to satisfy them.

In sum of the review above, Table 1 presents an abridged collection of certain possible pictures of smart electricity systems futures and their software-related developments. While it is not a comprehensive systematic

Table 1 Representative possible pictures of futures and their software-related developments

\begin{tabular}{|c|c|}
\hline Pictures of futures (exhibits) & Potential software relations \\
\hline \multirow{2}{*}{$\begin{array}{l}\text { Network operation includes full } \\
\text { observability and controllability of } \\
\text { the low voltage (LV) network } \\
\text { through the smart meters or } \\
\text { advanced equipment in the } \\
\text { secondary substations [22] }\end{array}$} & $\begin{array}{l}\text { - Intelligent Electrical Devices (IED) } \\
\text { in the networks embed more } \\
\text { software. }\end{array}$ \\
\hline & $\begin{array}{l}\text { - The network operations and } \\
\text { management systems incorporate } \\
\text { more software functionality. }\end{array}$ \\
\hline \multirow[t]{2}{*}{ Automated DR systems [25] } & $\begin{array}{l}\text { - DSOs have new operation } \\
\text { systems to control and balance } \\
\text { the grid loads. }\end{array}$ \\
\hline & $\begin{array}{l}\text { - New energy market solutions (e.g., } \\
\text { dynamic pricing) are implemented } \\
\text { as software applications. }\end{array}$ \\
\hline
\end{tabular}

Wind and solar power production - Software algorithms are used to will increase considerably [20] maintain the electricity network frequency balance.

- Transmission system operators (TSO) and DSOs utilize advanced software systems (e.g., DMS) to connect, operate and govern the new distributed energy resources.

- Additional data sources are incorporated (e.g., weather forecasts).

Electrical vehicles (EV) for energy storage [53] inventory, it denotes the background and our basic assumptions for the following software futures research. However, we do acknowledge that some of them may be of less necessity.

In conclusion, at this stage of our futures research process, we underscore the following assumptions:

- There will be more and more software and data in all layers of future electricity energy systems.

- These systems never "sleep." Consequently, the software must be developed and operated continuously (24/7/365).

- The enabled digitalization makes it possible to renew current processes and organizations-possibly even disrupting them with new business models (e.g., virtual power plant (VPP)) and emerging actors (in particular ICT/software companies).

- Other (non-energy) systems (e.g., EV) will interconnect and interoperate with electricity systems smart grids. Notably, there are also humanin-loops forming new CPSSes.

- In all, there will be new software-related dependencies which may cause unprecedented concerns (e.g., cyber-security).

\section{Positioning and focusing software futures research}

Following the energy systems developments and potentially important software-related scenario paths and their relevant present facts explored above, we can recognize future software-related key R\&D\&I avenues. It is instrumental to take a dualistic point of view:

1. The different non-software areas bring needs for software research and innovation.

2. The software research may introduce new opportunities and possibilities to utilize software solutions in the related fields.

The overall rationale for such interdisciplinary stance and positioning is that software is increasingly ubiquitous in modern electricity systems (smart grids), and the electricity systems themselves are increasingly coupled with other systems. For instance, the multi-level perspective (MLP) approach has been used as a middle-range theory to explain modern energy system transitions as sociotechnical processes with intertwined co-evolutionary interactions between multiple systems (technology, firms, markets, customers/users, culture, institutions) [5]. When electricity systems become more intimately coupled with different sectors such as transportation (EV), in the future new and more powerful types of models and their supporting software tools (e.g., simulations) are required to comprehend the resulting complex systems-of-systems [34]. In recent software-related research for instance, the 
BCDC program combines technical, economic, meteorological, and information science to address the multidisciplinary research topic of digitalization for flexible energy systems [6]. By and large, if we approach software futures in the energy systems considering digitalization in total, combining multiple different perspectives and disciplines also in non-traditional ways may be necessary [35]. In this paper, we aspire to make conscious bridging between software research, "hard" electrical engineering and "soft" human-oriented disciplines in the context of electricity systems-bearing in mind our computer science core competence.

Figure 1 represents our conceptualization of world with parallel developments on various energy systems related sectors in the society. The top of the figure represents the ongoing climate change and its cause, the global warming. The second plane from the top represents political actions, how our society is trying to affect to the ongoing global warming with policies and regulation. For instance, EU has set its climate and energy package and framework for 2020 and 2030, and its low-carbon economy roadmap for $2050 .^{1}$

In the middle of Fig. 1, there is a scenario path which represents the transition from fossil fuel-based electricity production toward more clean energy solutions, and further in the future, toward peer-to-peer energy economy. While this change might give much desired flexibility for the energy market, such change will demand novel solutions for storing the energy. Such economy will eventually enable end-customers sell and buy energy. This path is under the influence of the policies and regulation represented by the above plane.

At the bottom of Fig. 1, there is a path representing the customers and the "users" of the electricity and the evolvement of their possibilities to interact with the electricity systems. On this path, the user may be an end-user, an energy company, or it may be a third-party company focused on buying and selling electricity for instance. The user's needs are developing among with the new capabilities of the electricity systems, and most of these capabilities are built with software.

In between the electricity systems and the customer/ user, in Fig. 1, there is a path representing the progress of the software technologies. As mentioned above, the electricity systems have needs and requirements, but we see this as a cyclic process: The software is acting as a key enabling technology, but on the other hand, new requirements and needs are constantly emerging, and

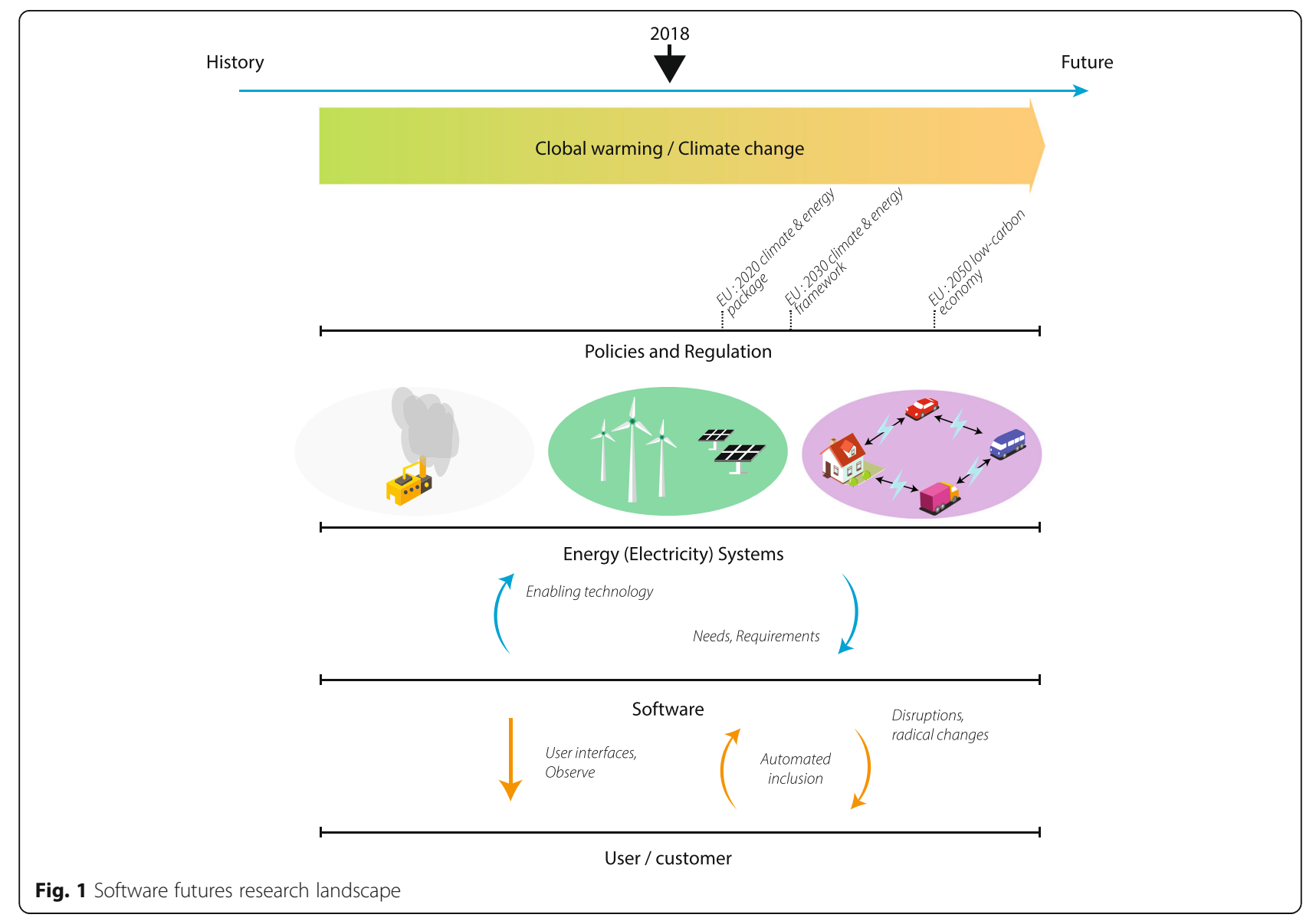


indeed, partly these new requirements emerge because of the technological progress of the software systems. Moreover, new software capabilities are making it possible to meet many of the future goals and regulations described above.

Between the user/customer and the electricity systems, the interaction is unidirectional at the moment, that is, the user/customer is typically only able to observe the energy consumption. However, we envision that in the future, it will be possible to have two-way (or multidirectional) ways to interact with the electricity systems as we will discuss later in this paper. For example, with the new technical devices and software systems, the user behavior is possible to observe and possibly even to predict to some point for energy saving purposes.

The focus of this paper is much on the software progress path of the Fig. 1, and how it fosters both, the development of the electricity systems, as well as the capabilities of the customer/user to interact with the electricity systems. Informed by the background reviewed in the above sections, we share the base picture of future that electricity systems smart grids will provide highly flexible and reliable electricity production, distribution and consumption infrastructure, and support versatile digitalized energy markets and data-based services. Our vision mapped to that is that such future smart energy systems are fundamentally software-enabled with "software houses." The scenario paths toward that incorporate new software competencies and capabilities of the related actors. Software is the key enabling technology for the development of the future smart energy software houses and systems. The modeling of the actual energy systems and related software tools for this task are, however, out of the scope of this paper.

Notably, we refrain here from judging specifically the preferability of the different possible developments. However, we do consider our vision of "software houses" desirable in many respects taking into account the past and present knowledge coupled with the currently available roadmaps.

As an overarching research method, we have tentatively leaned on the Futures Map [2]. However, whereas comprehensive future maps comprise all identified relevant pictures of the future and all their relations, here we refrain from developing pictures for future electricity systems and smart grids in total. Based on our computer science posture, we do environmental scanning of the software elements in future electricity systems following future scenario paths of the related systems elements and their inherent interdependencies. We do acknowledge that the time paths of the different scenario paths and roadmaps may differ considerably, but those systemic problems are not attended to here.
For the purposes of this investigation, several potentially applicable sources of pictures of futures, scenario paths, and roadmaps are available in public as inputs for our software-focused futures research. Table 2 presents certain relevant ones allocated to our overall futures research landscape framing in Fig. 1.

Focusing on the software sphere in Table 2, we address that line of thinking with the following overall software research problem (RP) formulations:

1. What software is there (going to be) and where all over the future energy systems (Smart Grid architecture)?

2. What particular software technologies and competencies does (could) software in there involve?

By software we mean all ICT-based intangible infrastructure elements and ICT-enabled solution artifacts. Software competencies are knowledge, skills, and experiences to define, design, and implement software. Software capabilities denote organizational assets to utilize the competencies for developing, acquiring and using software operationally.

Investigating the former question (RP1) makes it possible to discover potential future opportunities for more software solutions on the one hand and to realize the prevailing current software-related energy system needs

Table 2 Past and present pictures, scenario paths, and roadmaps for software-related futures mapping

\begin{tabular}{ll}
\hline Sphere (Fig. 1) & Related scenarios, roadmaps \\
\hline Climate change & $\cdot$ UN 2030 Agenda for Sustainable Development [54] \\
Policies and & $\cdot$ EU 2030 Energy Strategy [55] \\
& $\cdot$ Electrification (in the large) [7] \\
& $\cdot$ Low-carbon transitions [4] \\
& $\cdot$ Energy landscape changes [18] \\
Energy (Electricity) & $\cdot$ SGEM: Smart Grid development, Markets [22] \\
systems & $\cdot$ European Electricity Grid Initiative (EEGI) [21] \\
& $\cdot$ European Network of Transmission System \\
& $\cdot$ Operators for Electricity (ENTSO-E) R\&D\&l [12] \\
& $\cdot$ Grid edges [8] \\
& $\cdot$ Rural area netwrification (power systems) [7] \\
& $\cdot$ Next-generation grids [57] \\
& $\cdot$ SGEM: Technology [22] \\
& $\cdot$ EU Software technology research [58] \\
& $\cdot$ SGEM: end-user [22] \\
Software & $\cdot$ Rural energy system customers [56] \\
& $\cdot$ Urban energy system users [59] \\
& $\cdot$ Consumer behavior changes [51] \\
User/customer &
\end{tabular}


and obstacles on the other hand. The latter question (RP2) then informs our designations of software competencies and capabilities for the future energy system "software houses." By the software houses we mean all such organizations (actors) for which software development (acquisition) and utilizing software in operations are inherent core competencies and capabilities. Software elements and data are seamless key parts of their offerings and/or operational capabilities.

In this paper, we do not aim to go systematically into details on software actually used in different cases. Instead, we provide an overview of areas where software is applied and illustrate that with some examples in certain detail. That serves the purpose to frame and scope our futures research for smart energy (electricity) systems.

\section{Computer science perspective: software systems and data}

The research and development of smart grids is multidisciplinary. Even within the principal computer science discipline, there are many relevant software-related realms ranging from core CS (e.g., programming, databases, networking) to empirical software engineering and information systems development (ISD).

For the purposes of this paper, we take the following overall perspective of CS in the context of smart grids:

- COMPUTATIONS, COMPUTING (algorithms, processing)

- COMMUNICATIONS (distribution, remote access, information exchange)

- INFORMATION, DATA ("smart," intelligence)

In the following, we give a framing overview and some exhibits of software and data in electricity systems smart grids. While data can in principle be independent of software implementations, in practice all digital information processing and storage in smart grids is based on software systems (ICT). Notably, this is not a comprehensive review but the purpose is merely to ground and reason our assumptions for the future "software houses." Following this grounding, the next section of the paper then elaborates what modern software technology and future software engineering advances could enable with different kinds of data and potentially new kinds of uses.

\section{Software in smart grids}

In the CS perspective, modern electricity systems smart grids are complex system-of-systems (SoS) with significant software parts. The evolution of the current grids to integrate new technologies, in particular ICT, couples power systems with software systems. It follows that future power systems engineering, operations, and management concern increasingly software applications, services, and communications. Furthermore, smart grids can be regarded as software-based service platforms for future distributed, energy systems $[9,11]$.

In order to address our RP1 in systematic and comprehensive ways, we need a system architecture model of modern electricity systems smart grids. The Smart Grid Architecture Model serves such purposes [3].

SGAM represented in Fig. 2 is a layered architectural model that consists of the following five layers:

- Business layer represents the business view on the information exchange.

- Function layer describes functions and services including their relationships from an architectural perspective.

- Information layer describes the information that is being used and exchanged between function, services, and components.

- Communication layer describes the protocols and mechanisms for the interoperable information exchange between the components.

- Component layer represents the physical distribution of all participating components.

The foundational architectural design property is the interoperability between the layers (planes). There are interfaces between the domains and zones normally on the information layer. However, there are also interfaces between the planes. Typical data (information) exchanged between the layers are measurements and control signals.

The key principle of the SGAM model is to separate the electrical process physical domain energy conversion chain and the information management hierarchical zones. Consequently, it bridges the traditional energy management and ICT disciplines. It is thus fundamental to see the software in the power technology domain context. However, on the other hand, modern software architecture expertise brings necessary new competence for the overall systems engineering and management of the entire smart grids as CPSes.

From our software point of view, we can see the SGAM framework overall as follows:

- Electrical process domains: embed software

- Power system information management zones: use software

- Interoperability layers: incorporate software

As a concrete example of the SGAM information processing modeling (derived from a use case "Control reactive power of DER unit" [3]), Table 3 illustrates what kinds of software operations could be allocated to different computer-based actors and in the grid (c.f., Fig. 4). 


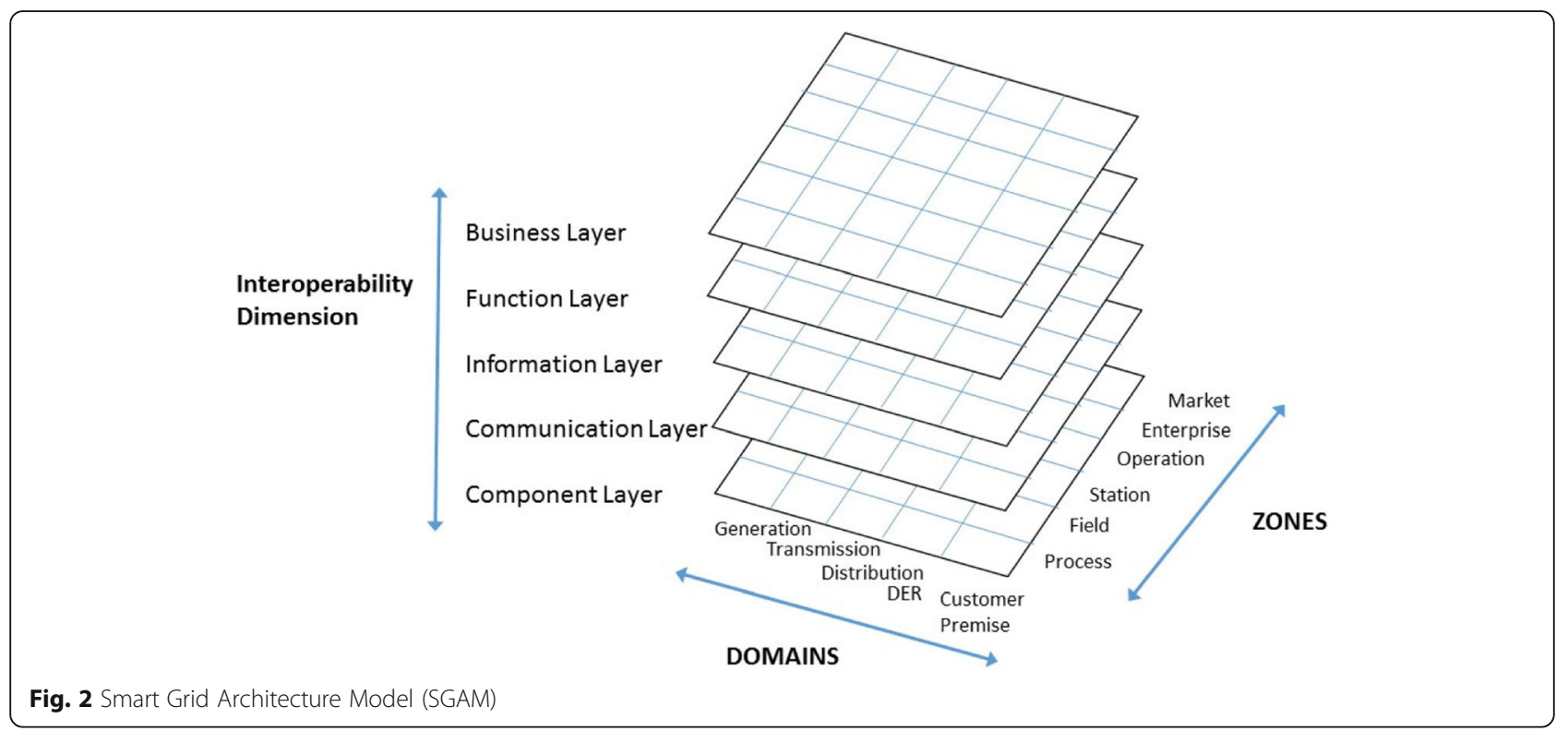

Notably in addition, all those must be integrated as a system with interoperating information exchanges.

\section{Data in smart grids}

In addition to software realizations (code), there will be much more and diverse data in smart grids. There are already a lot of new digital data sources originating for instance from the smart metering (AMR). The data must be acquired and exchanged, resulting in new data streams and information flows across the grid. Furthermore, all the data must be stored and shared for example with data hubs.

ICT can be seen as an enabler for smart grids by providing the information processing of the digital data. However, in order to achieve that it requires common interfaces and data models (data management). These are essential software-related concerns in the information and communication layers of the SGAM architecture framework (see
Fig. 2). From our software point of view, the following are then key considerations (CS knowledge):

- Availability, access, ownership, information security

- Open interfaces (API), sharing (standards)

Once those data management issues are resolved, there are even radical opportunities for exploiting data with new software solutions. Typical ones include monitoring and predicting the state of the electricity system (e.g., outages, DERs, demand forecasting) by combining and analyzing different data sources (even big data).

Continuing the practical example depicted in Table 3, there are various different data acquisitions, processing, and exchanges needed to implement such a system use case with software. Some of them could be the likes in Table 4.

Table 3 Software realization example (use case of controlling power of DER unit)

\begin{tabular}{|c|c|c|c|c|c|}
\hline & Generation & Transmission & Distribution & DER & $\begin{array}{l}\text { Customer } \\
\text { premise }\end{array}$ \\
\hline \multicolumn{6}{|l|}{ Market } \\
\hline Enterprise & & & CRM computer: system reports and analysis & & \\
\hline Operation & & & $\begin{array}{l}\text { DMS computer: monitoring and controlling distribution } \\
\text { system equipment }\end{array}$ & & \\
\hline Station & & & $\begin{array}{l}\text { Distribution data collector: data acquisition from } \\
\text { multiple sources and reformatting }\end{array}$ & & \\
\hline Field & & & $\begin{array}{l}\text { Distribution IEDa: } \\
\text { monitoring automated devices in electricity process } \\
\text { distribution }\end{array}$ & $\begin{array}{l}\text { DER Controller: electricity process } \\
\text { controls }\end{array}$ & \\
\hline Process & & & & & \\
\hline
\end{tabular}


Table 4 Software realization example (use case of controlling power of DER unit, cont.)

\begin{tabular}{|c|c|c|c|c|c|}
\hline & Generation & Transmission & Distribution & DER & $\begin{array}{l}\text { Customer } \\
\text { premise }\end{array}$ \\
\hline \multicolumn{6}{|l|}{ Market } \\
\hline Enterprise & & & CRM computer & & \\
\hline Operation & & & $\begin{array}{l}\text { DMS computer: Sending the calculated control } \\
\text { information to the power system controller (DER } \\
\text { Controller) }\end{array}$ & & \\
\hline Station & & & $\begin{array}{l}\text { Distribution data collector: Passing the } \\
\text { measurement information to the system process } \\
\text { calculation functions (DMS) }\end{array}$ & & \\
\hline Field & & & $\begin{array}{l}\text { Distribution IED: getting the (real-time) } \\
\text { measurement values of the actual power system } \\
\text { state }\end{array}$ & $\begin{array}{l}\text { DER Controller: receiving the calculated } \\
\text { control information and sending the } \\
\text { power system process control signals }\end{array}$ & \\
\hline Process & & & & & \\
\hline
\end{tabular}

Moreover, DSOs could value their smart metering and other grid data assets for new digital services. That is the software space in the business layer of the SGAM.

\section{Future software-related dependencies and opportunities}

Characteristics of the software include vastly progressing technologies, more and more powerful programming abstractions, and the software pervading to all areas. Indeed, the software has revolutionized many areas in our increasingly electricity-dependent society. Since future electricity systems become more and more software-dependent, it follows that software plays a major role in the future energy-related CPSSes in total. It is thus instrumental to both realize the new and emerging software dependencies as well as to foresee the state-of-the-art software technological opportunities.

\section{Software-related dependencies}

When the role of software in future electricity systems grows, there will be more software-related dependencies in all layers of the SGAM architecture (Fig. 2). The specific grid dependencies stem from the actual system technology solutions, but some of the typical inherent areas are the following:

- Interconnectivity, communications (communication layer)

- Data/information/knowledge exchanges (information layer)

In addition, notably, there are many cross-cutting issues in smart grids that introduce new system-wide software dependencies. Certain such key ones are:

- Safety, reliability

- Cyber-security (particularly information security)
It is imperative to be able to distinguish all those software dependencies systematically covering the entire smart grid architecture design and implementation (e.g., including externally provided IT platforms). Failing to do so may cause extra costs for instance in the system integration and more critically even endanger the whole electricity system stability and reliability.

The cross-cutting issues are often network-wide (e.g., trusted end-to-end data communications). Consequently, their engineering and operational requirements must be taken into account upfront to begin with but also during the real-time operations of the electricity systems (e.g., intermittent security vulnerabilities or reliability risks). Systems thinking and software systems engineering competencies are needed increasingly.

\section{Software-based opportunities}

Modern software technology and ICT offer significant opportunities to develop future electricity system smart grids. Since many smart grid deployments are in practice evolutionary developments of existing electricity networks, the software-enabled improvements may be incremental steps (transitions). However, with advanced software knowledge and competencies, there are opportunities to create even radical, systemic changes (transformations).

One current developmental trend is modernization of current grids with new or additional software-based solutions. One of the key steps there is the replacement of conventional consumer metering with smart meters and AMI. Similarly, for instance, substation automation systems may be upgraded with software to become more intelligent and allowing advanced remote controls. These then enable new network functions and operations-but also create new software-related dependencies (e.g., software configurations management and deployments).

Another current trend is the system IT and OT (operational technology) convergence. There for instance 
general-purpose standard hardware and IT platforms may be used in both, making it possible to leverage common competencies. Creating new digital services with the new data/information sources is a rich field of software-enabled opportunities. However, utilizing them requires new software-related competencies which may not be readily available in traditional electricity companies.

Advancing in the system level, the notion of virtualization opens up opportunities for even radical changes. A notable recent advancement is the concept of VPP which is intrinsically software-enabled. Consequently, developing such new power system architectures (CPS) requires extensive software competencies for instance to allow system-wide information exchanges to operate such a dynamically configurable system.

The following identifies such emerging paradigms and concepts changing how software systems operate and are being developed. It also recognizes some of the latest software engineering research and presents our hypotheses for leveraging these in future energy systems.

\section{Fog computing}

The standard connectivity technology (e.g., WiFi, Bluetooth, mobile broadband, Narrowband IoT) and computing technology (integrated circuit technology) enable interconnecting an ever-increasing number of physical entities, leading to the Internet of Things and the Industrial Internet. While Cloud computing has been defining the way how software is developed the past decade, now the latest advancements in the networking technology and computing infrastructures are enabling a new Fog computing paradigm. This brings the computation capabilities all over to the network topology, leading to an entirely new type of computing infrastructure.

The shift in the computing paradigm from computations in the cloud toward the network core and network edges has been depicted in Fig. 3: On the top, Cloud-based technologies yet have an important role acting as storage services; offering synchronization between remote entities; as well as offering analyzing the big data-although now more and more analysis takes place on the network edge devices and intelligent, smart nodes. In the middle, the smart gateways and intelligent network nodes provide a new type of infrastructure for computations to take place near the network edges, where people and their devices are actually situated as has been depicted at the bottom of Fig. 3 .

Many benefits of this shift come from reduced lag in the communication and the more local computations. The former is fostered even more in the coming years while commercial 5G networks are established as those promise to reduce the communication lag close to 1$10 \mathrm{~ms}$. In the meantime, the already existing networking technologies can be used for direct device-to-device communication. The minimum lag opens new possibilities for more real-time applications that are critical for many energy systems.

The actual energy system benefits, however, come from the local computations, that take place all over on the connected entities of the smart grid. While smart grids have been studied for many years already and in the existing energy network systems there naturally already exists various kinds of intelligent decentralized computations on the grid nodes, here, in this paper and context, with the local computations we refer to the possibilities of third-party companies to execute their software where it makes the most sense from the point of view the benefits discussed already in this paper. The local computations enable virtualization of many services, like the virtual power plants for example.

The direct device-to-device networking capabilities enable forming coalitions between trusted devices which is fostering the smart and flexible ICT-based distributed energy systems [36]. For instance, in order to improve the functional safety of the system secure and trustable connections are vital so that these highly critical systems can operate even in situations and under conditions where the Internet connection becomes slow or is lost completely at the times. The trusted networks are also the basis for keeping the private data safe from outsiders and possible hostile third parties.

Some recent technologies foster Fog computing include microservice architectural style, and serverless computing [37]. In the former one, the idea is that the system architecture is decentralized and based on numerous small services that each have only one single responsibility in the system. Noteworthy is that although each microservice type only one feature on its responsibility, yet many instances of that type can be created. This makes scaling the system more easy, which improves the quality of service. Additionally, this can improve the functional safety of the system since microservices are fast to launch to replace malfunctioning or unreachable microservice instances. Despite of their many benefits, however, microservices and moving from traditional monolith service architecture to microservice architecture have also many challenges as we have studied earlier [38].

The latter one, serverless computing paradigm, has been emerging vastly during past years. The main idea is that the developer (and the maintenance team) is freed from thinking about the back-end infrastructure since: the developer simply deploys the functions to a system that executes a function when requested. This kind of serverless computing function can do many things, like save data to a database/storage, do a some computational operation on a remote entity, utilize some specific 


\section{The Fog Computation and Coordination}

Fog Computing enables performing the computations

closer the data's origin, and coordination closer to

the location where the actuation and interactions take place.

울

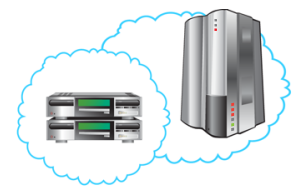

Sensor data \& actuation instructions

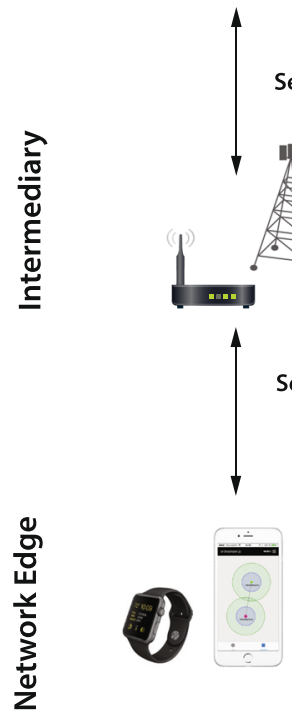

Devices and Peripherals

Personal and non-personal devices able to collect data and actuate with the physical world. Can also

communicate directly with other

devices (without intermediary)

ensor data \& actuation instructions
Cloud Services and Storage

Scalable computation and

storage services are provided by

many companies. Easy to set up,

scale, backup support, etc.

Users' privacy may be at risk in

some cases.

Gateways and Hubs

Used for transferring data and actuation instructions between cloud and devices. Becoming

increasingly capable and can

be used for computation.

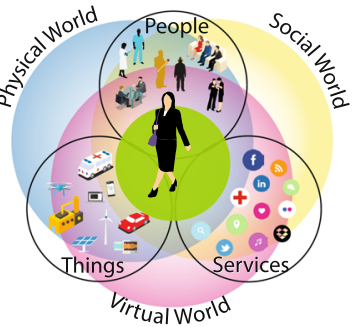

Humans and the Environment People, Things and Services which interact in Physical World Social World, and Virtual World.

Fig. 3 Fog computing and the modern computing environment

service, and so on. Despite that serverless computing is relatively new paradigm, already many cloud service providers are offering their pay-per-use services (e.g., Amazon AWS Lambda, ${ }^{2}$ Google Cloud Functions, ${ }^{3}$ Microsoft Azure Functions, ${ }^{4}$ etc.). Indeed, such usage-based billing is considered also as one of the biggest benefits of the serverless computing and can offer great saving in some types of services where the paradigm fits well as we have studied in [39]. Like in any technology, however, there are pitfalls also in serverless computing and the developers must be aware of these as pointed out in [40].

Component layer in Fig. 4 represents the physical distribution of all participating components in SGAM. The physical structure of this layer consists of multiple interconnected entities that communicate and collaborate with other entities on the same and different zones and domains. These components can for example be data controllers or gateways. Thus, the SGAM and infrastructure 


\section{Component Layer}

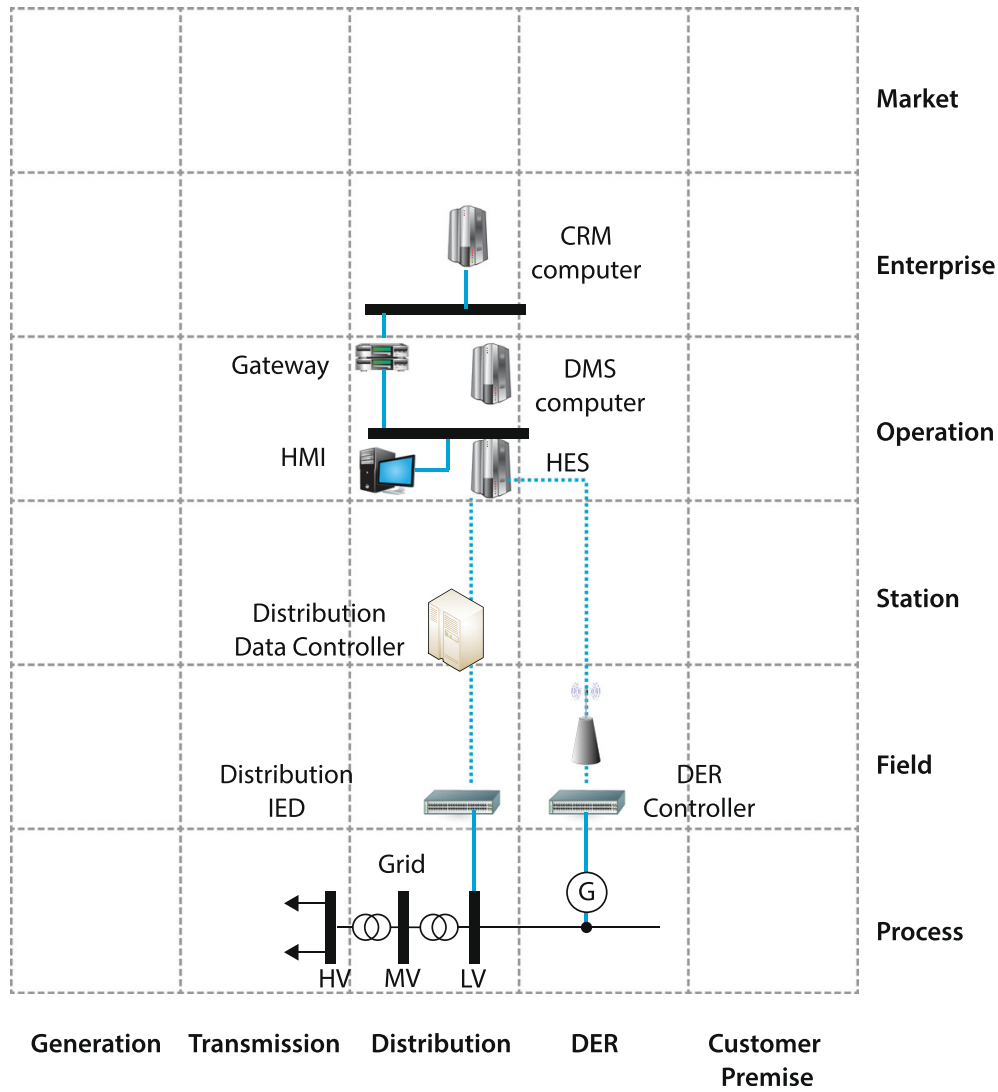

Fig. 4 SGAM component layer illustration (derived from [3])

can be considered as an instance of the modern Fog computing environment where computation takes place on various entities.

Overall, the above-mentioned emerging paradigms, technologies, networking infrastructures, and software paradigms form the basis for the modernization of the electricity networks, since these can be considered as a concrete Fog computing infrastructure. Such infrastructure will help to enable new types of multi-directional connections and digital services that can only be constructed with (third-party) software that operates on various decentralized nodes and local computations in the smart grids as well as in other network nodes.

\section{Physical-cyber-social computing}

Physical-cyber-social (PCS) computing was first introduced by Sheth, Anantharam, and Henson in [41] in 2013. Also, others have introduced CPSSes, CPS computing approaches, and wide range of applications with very similar ideas than the PCS computing approach as shown by the survey Zeng et al. [42]. Some of the oldest CPSS references are from 2010 to 2011 [43, 44]. In this article, we have mainly used the term CPSS while referring to cyber-physical systems that also incorporate the social dimension (or social world).

PCS computing main idea is encompassing data, information, and knowledge coming from the physical, cyber, and social (PCS) worlds and then to integrate, correlate, interpret, and provide human-understandable abstractions that are contextually meaningful [41]. According to the authors, this improves the human experience in computing [45]. They present in the article an example of applying PCS computing on healthcare where sensitive information is being complemented with information from the Internet to provide more understandable and accurate results.

PCS computing is built on the data-information-knowledge-wisdom (DIKW) hierarchy/pyramid with horizontal and vertical operators: The horizontal operators harness information from heterogeneous, multi-modal sources, that is, from different PCS dimensions (e.g., various sensors attached to human body). The vertical operators, on the other hand, aim at translating the observations from low-level data to a high-level knowledge. This process has been depicted in Fig. 5 . 


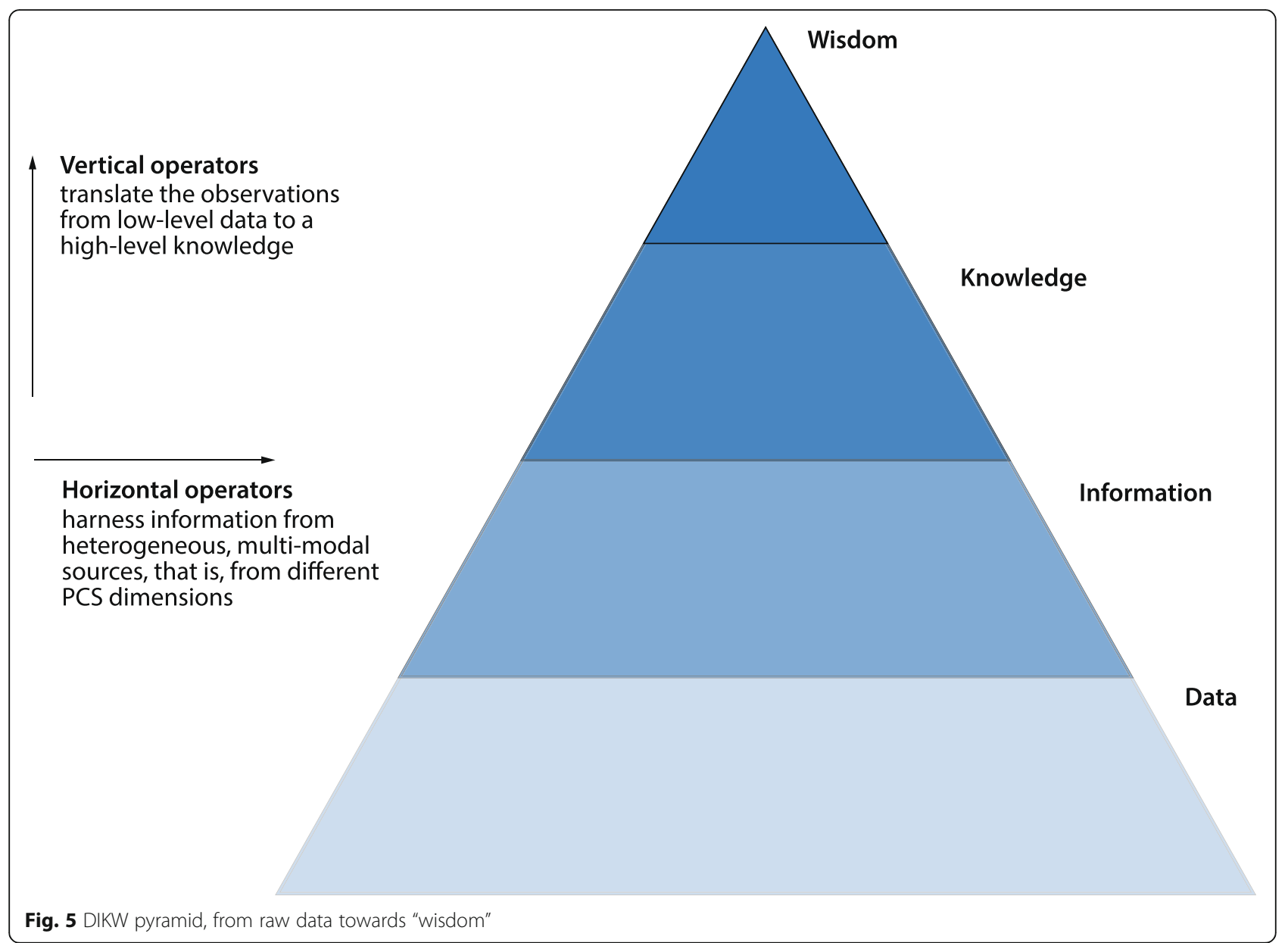

In smart electricity systems, similar approach could be followed for tracking human behavior and for enabling two-way interactions with the electricity systems: The data coming from the various PCS worlds are valuable for understanding the human, and possibly predicting their behavior. Consider for instance that your smart home systems would know when your family members are home-the system could then adjust the air condition system or heating based on some predictions. Similarly, an electric vehicle battery could be used for buying and selling energy from/to others when that makes sense based on the end-user behavior. Sowe et al. for instance write that in contrast to most systems that simply try to satisfy one user's goals, the people can help the system make intelligent decisions and achieve goals that ultimately are people's goals [46]. What such predicting behavior would require, however, is software technology that can collect, analyze, and use information the CPS worlds.

\section{Picture of future (PF1): From raw data to programmable abstractions with human data model}

Human data model (HDM) is our latest CPSS approach which can be viewed as a scenario path, eventually leading to our vision of future smart energy software houses: HDM enables useful and programmable data abstractions-HDM sensations-to support micro managing energy smart systems on the consumer level. The sensations are composed and refined from data coming from various worlds. In HDM, the virtual world and the physical world merge into each other. The third dimension-the social world-is crosscutting the physical and virtual worlds, reflecting the social relationships and interactions. This is illustrated in Fig. 6 which also positions the people, the devices, and the services into these worlds. HDM operates in the Fog, that is, it leverages the computational power available in the highly decentralized network infrastructure, allowing performing computations on various network nodes, and keeping data in its original source. The data coming from the various worlds are combined in order to produce higher level information that can then be easily intuitively programmatically leveraged in third-party software applications. Human data model develop under open source license (available on GitHub ${ }^{5}$ ), which we believe is essential for such component and computing infrastructure. 


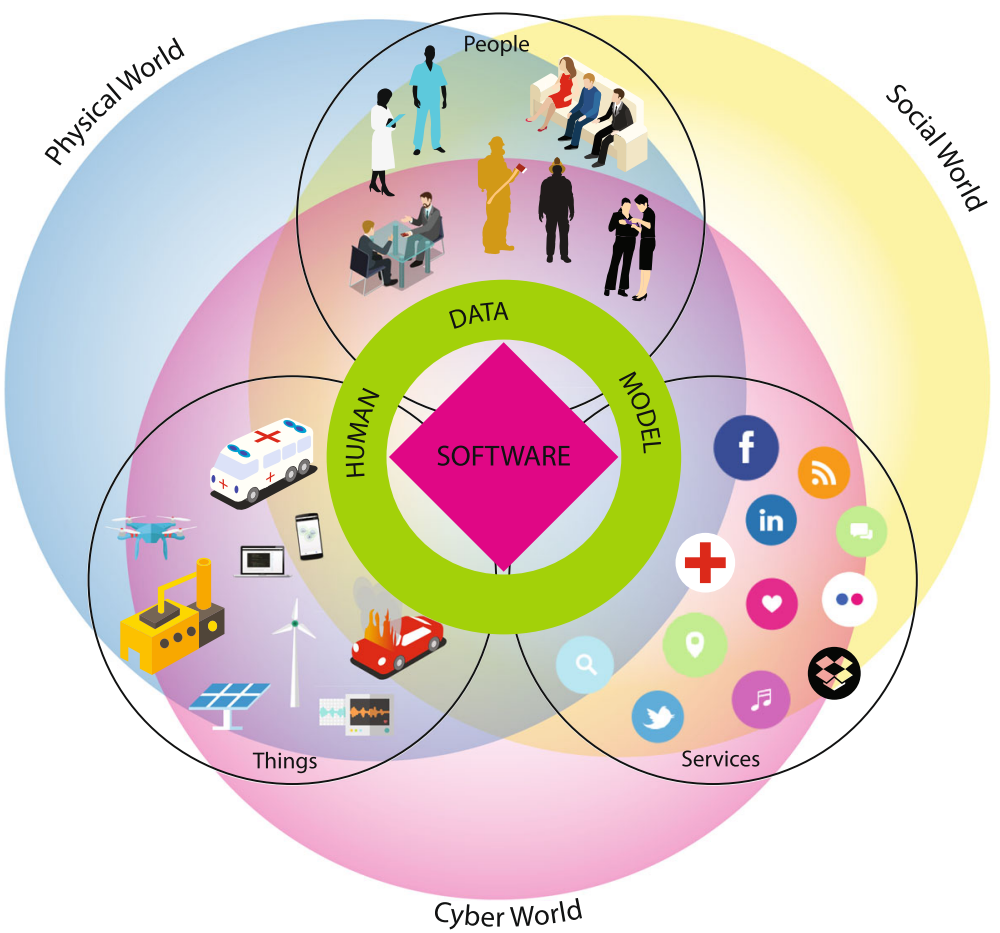

Fig. 6 Human data model. Leverages data from the social, cyber, and physical worlds and refines them to more meaningful abstractions for programmers and end-users

Human data model is based on the following four qualities that follow the DIKW pyramid's horizontal and vertical operators and support implementing software where human is in the core:

1. HDM enables harvesting data from the social world (e.g., social media services), the cyber world (e.g., online tools and services), and the physical world (e.g., various sensors attached to human body). This process follows the DIKW (data-informationknowledge-wisdom) hierarchy/pyramid horizontal operators: HDM allows harnessing data from heterogeneous, multi-modal sources. Developers are enabled to implement handlers for new types of raw data inputs for HDM.

2. HDM enables translating the raw input data to information, and information to knowledge, and thus follows the DIKW pyramid's vertical operators: HDM supports refining and analyzing the observations from low-level data to a high-level knowledge. The software developers are enabled to program their own methods for refining the raw data from the sources they are interested in. On the horizontal level operators, the developers are enabled then to combine this data to other data stored in the HDM instance.

3. HDM enables learning from users by allowing their feedback about the produced sensations.
Understanding how different data correlate is essential as it will enable the knowledge then eventually to become the "wisdom" - the user and the model have a consensus how the sensations emerge and how will these affect. Deep learning and neural network computation approaches can also be integrated as part of this learning process with human data model's computational model and by sharing the sensation and the training information with other HDM instances. This ability to learn will form a path for making the electricity systems smart and better serve the users' preferences as well as support the green economy.

4. HDM enables observing changes and accessing the sensations (data, information, knowledge, and wisdom) safely and predictably and integrating these into the modern electric systems. The user (or the owner of the original data) will always be aware of which operations are empowered to use which data.

HDM sensations that can help the software programmers to implement new types of services (e.g., proactively suggest selling the energy). This may also help to make the smart energy systems more self-adaptive, that is, the systems reserve resources on-demand manner, forming micro smart grids in automated ways for various purposes (e.g., to recover from power cuts), and 
eventually it is possible to affect the end-user energy consumption.

We have already considered the following HDM sensations about human body and surroundings. Notably, the first ones are closely related to energy (electricity) systems:

- Technical environment: devices in the proximity and the interaction with them

- Environment information: temperature and humidity

- Lightning: brightness and color

- Location inside a building

- User or device location on a map

- Symbolic location (e.g., "commuting by train," "at work," "home")

- Safety and surveillance-related information (for instance when elderly people are home alone)

- Acoustic information: volume (e.g., noise level) and pitch/frequency

- Mechanical information: position, acceleration and strength

- Biological information: heartbeat (heart-rate), skin temperature, nerve system activity, and respiration rate

- Blood sugar level, blood pressure, and weight

- The amount and quality of sleep

- Ongoing activity (e.g., walking, running, working, watching TV)

- User-generated stored information: e.g., written text, taken photos, and shot videos

- Sports performance measurements (e.g., heart rate, distance, speed)

- Social environment: people in proximity and the social interaction with them

- User's activity and interactions in social media (e.g., Twitter, Facebook, WhatsApp).

We conducted a web survey (274 professionals working in technology companies and universities) about the above HDM sensations. All these sensation types were well received, and most people believed that these would help their organizations to implement new types of services. These sensation types were estimated to be useful, and in total $78 \%$ of the people said that they believe their organization would be interested in implementing new services if using such information would be easy. We will revisit some of these initial HDM sensation types above and describe how such human life-related information will become highly important while moving towards more human-centric Internet of Things. The idea, however, is that the software developers are empowered to define their own, even more high abstraction level sensation types with HDM (quality \#2).

\section{Internet of people}

The Internet of Things aims at connecting the physical things to the Internet (or other networks). While this opens up many possibilities, the goal is not, however, profoundly user-friendly-already today, we use multiple devices (e.g., laptops, smartphones, tablets, smart watches, etc.) which have made us more glued to technology than ever before, and these devices now expose us on a vast amount of interactions with them. With the ever-increasing number of interconnected IoT devices, the amount of manual interactions requiring human awareness is in danger to grow exponentially.

The Internet of People (IoP) [47] paradigm aims at the opposite direction: the goal is to minimize the manual interactions and interventions required from the user. Previously, we have put together the Internet of People manifesto [47], which defines four main principles how the human interactions with the machines should work. These are introduced in the following.

1. Principle 1: Be Social. Interactions between the humans and machines should be social. This means that the IoP should allow for heterogeneity by supporting the various types of machines that humans use and let them interact with each other and with humans more socially than does the IoT. Moreover, being social, from the human perspective, also requires leveraging interaction modalities that are the most convenient and which feel the most natural for the human users.

2. Principle 2: Be Personalized. Interactions between entities must be personalized to each users' preferences as well as to the environment where the interactions are taking place. In other words, this means allowing for contingencies and providing a transparent mechanism for this customization. Moreover, the interactions must consider the sociological profiles of all participating people. Similarly, each participating user must be empowered to adjust their preferences to control how others use their profile.

3. Principle 3: Be Proactive. The interactions between the things and people must proactively take place so that the user must manually initiate not all the interactions. Today, most use cases where multiple devices participate only consider remote interfaces for managing the connected devices. More and more devices online mean more and more distractions and work in managing these devices. Thus the interactions should allow all types of devices to initiate interactions with people and other devices proactively. Naturally, however, the users should be offered means to adjust how 
proactive the interactions are and when these interactions take place.

4. Principle 4: Be Predictable. Interactions with things and people must be predictable. The predictability here means that the interactions should trigger according to a predictable environment that the user has previously identified, and for which a specific behavior has been defined and given permission to take place. Users must be empowered to identify and tag that environment, specify the expected behavior of the entities involved, and set the privacy policies for sharing their information by being advised of what information they are sharing and with whom. Given that the complete predictability of interactions is hard to achieve, the user must always understand how the interaction can be stopped immediately and also teach the system how to prevent the misbehavior in the future.

There are many ways to realize the IoP and its manifested principles. Central to all the Internet of People approaches is that the human in the core of the interactions and in these, the above presented human data model sensations will become useful. Other closely related approaches are social devices and people as a service (PeaaS) concept. PeaaS considers smart phones as virtual representatives of their owners [48]. The same idea is also behind social devices concept which considers smart phones as a companion device that reflect their owner's preferences to the surroundings [49] and then the interactions between the other devices in the surroundings to be proactive and social. Indeed, the mobile phone at the moment seems like the most natural choice to represent the user to other devices. It also adds another possibility-hold all the sensitive and possibly even intimate information and data on the user's possession. For instance, the PeaaS model holds all the information on the phone and the services request the information from there. This is opposite for the most approaches of today where all the information is stored on a numerous third-party services and the user cannot be exactly sure for which purpose this data will be used and who will gain access this data. (The terms of the service may change).

It is evident that by knowing the user, the two-way interaction and automation becomes possible. The principles in the IoP manifesto give a good mindset and a starting point for thinking about this integration. As an example, in [47], we presented a blueprint architecture for IoP and how this can be integrated to services like traffic control system and smart homes. We also presented a picture of future to describe how the system would work, and how this integration helps saving energy and other resources. Similar integration indeed becomes possible with smart grids, and especially in the context of Fog computing, and can then be applied in smart energy systems.

These software competencies could direct response to some of the missing competencies identified by Heiskanen and Matschoss in their article based on eights use-cases about sustainable smart energy systems [50]. Moreover, together with the human data model and its high-level sensations (abstractions, described above), software following the IoP manifesto could truly help the end-users (customers) to contribute and help them build and customize their own energy consumption in more innovative ways. Such demand for consumers as innovators has been studied and the need for such consumer-oriented innovation on the energy sector has been identified by Heiskanen and Matschoss in [51].

We envision that by following the human data model scenario path, it is possible to reach the following pictures of futures (and eventually the vision of future smart energy software houses) that is based on the Internet of People principles.

\section{Picture of future (PF2): Personalized, proactive temperature adjustment based on the preferences of the people}

To save energy, the electric heating system should consider the people in the room (P1 (principle 1) and P4) and compute the preferred temperature based on (P3) for adjusting the temperature (P2). This can be achieved by observing sensations on the user's body measurements (e.g., skin temperature) to detect if the user is feeling hot or cold, and by forecasting where the user is expected to spend some time next (history of user's locations and activities at certain time on certain weekdays). For example, after exercising or during night time, the temperature can be automatically adjusted to optimize the convenience and sleep quality for instance. In an office room or home, the heating can be turned lower if nobody is detected to be present, and also the heating can be adjusted to a preferred (computed) temperature prior the user is expected to arrive at work/home. To avoid unnecessary heating will save energy. Also, with efficient heating during winter time for example, the temperature often may become too high. If the temperature is computed to become too high, it makes sense to adjust in advance the temperature to preferred (computed) temperature compared to traditional old way: open the window and let the heat out when there is too hot inside, as the preferences are hard to predict "manually." With HDM sensation, such predicting becomes possible. HDM then operates in a decentralized way in the electricity system (e.g., at work place/home), to represent the user and communicates and exchanges sensations with the other instance of the user's HDM 
instances (e.g., on user's mobile device and wearable devices) to predict the user's preferences for the temperature. The computed preferences are also shared with other family members/colleagues to adjust the temperature so that it is convenient for all.

\section{Picture of future (PF3): Proactively selling energy for the local community}

The prosumer's solar and wind power system can predict based on the personal profile (P2) when the user does not need the energy (P4) and when it is profitable for the prosumer to proactively sell (P3) the energy for one's local community (e.g., neighborhood or other summer houses on the same area) (P1). Human data model sensations provide information about the user's current location and upcoming activities and plans (e.g., holiday plans based on calendar entries). These sensations form a behavior model of the user which helps the system to be trained for asking user about willingness to sell the energy based on these sensations. If the predictions are wrong, the system learns this and uses alternative strategies for the selling suggestions. Human data model instance then must operate on the smart grid to represent the user/prosumer for buying/selling the energy based on the demand. The user's HDM instances communicate and exchange information directly with the user's other instances (e.g., the one running on the user mobile computing device) which then may ensure from the user (eventually the system must learn this behavior) if the detected demand or free capacity is correct and the system is allowed to perform buying/selling actions based on this interpretation. While such software enables the local peer-to-peer energy markets, it at the same time helps balancing the smart grids' capacity. For instance, it may be profitable for one user with contract with certain terms with certain electricity company to buy electricity from the main electricity network and then sell this for the others who typically rely on their own solar panel system when the electricity demand is very high (e.g., during rainy holiday season on a summer house area).

\section{Picture of future (PF4): Collective commuting with electric cars}

Electric cars can be leveraged for social carpooling system (P1) where people living in the same areas and working near the same destinations are proactively proposed to (P3) share rides when their schedules match (P2 and P4). HDM provides sensations about the user's current location and social relationships (e.g., based on LinkedIn social network), and ongoing activity. Together with these sensations and entries on the user's calendar, the social carpooling system can predict the user's schedule and then suggest carpooling for the following day. The system can automatically select the car which is available (not reserved for another family member for instance). The system will give credits for the user whose car is used, and then use this information as a basis for the upcoming carpooling recommendations. Human data model then operates at the edge (of the network) on the users' electric cars and mobile devices (or alternatively on the Cloud to access the calendar services). Moreover, this picture can also be linked to PF3: the cars that are not being used for commuting can be used for selling the energy during day time, when the demand for electricity typically increases. In addition to the prosumers electric cars, human data model then operates also in a decentralized way on the smart grid network as a virtual representative of the user/prosumer.

As pointed out by the pictures of futures above, users do not necessarily need to give up anything while saving energy. Instead new, better, and more convenient solutions can be developed with software and data. These solutions will also help saving energy and, in some case, even enable new peer-to-peer economy of prosumers for earning money with the future energy systems.

\section{Potential emergent software-based pictures of futures and scenario paths}

Table 5 summarizes the pictures of futures described above and some potential (incomplete) pathways toward our vision of future smart energy software houses. Those are intended to serve as our creative inputs for the further futures research to construct a comprehensive $\mathrm{Fu}$ tures Map.

\section{Future software competencies and capabilities}

The leading objective of this paper in the current stage of our software futures research is to exhibit how necessary future software competencies and "software house" capabilities can systematically be recognized. In the preceding sections, we have explored what all software there is in modern smart grids. Furthermore, we have envisioned future opportunities for applying latest advanced software technologies. Grounding on that understanding, we can inference key software competencies and future smart grid "software house" capabilities. This is how we address our RP2.

In our future vision, if energy systems organizations desire to become proficient "software houses," their scenario paths entail systematic software competence and capability development. Our contribution here is to provide guiding inputs for that. However, our intention is not to compile comprehensive competence inventories. The aim is merely to present a framework demonstrating how each future "software house" can rationally derive their specific software competencies in their smart grid systems contexts. We have earlier composed such gauging for "software houses" in general elsewhere [1]. 
Table 5 Possible software-based futures and potential relations to smart energy systems

\begin{tabular}{|c|c|c|}
\hline \multicolumn{2}{|c|}{$\begin{array}{l}\text { Software enablers, software-based pictures of futures, and software-enabled } \\
\text { scenario paths }\end{array}$} & \multirow{2}{*}{$\begin{array}{l}\text { Potential relations to smart energy (electricity) systems futures } \\
\text { - SGAM can be seen to become or represent a true Fog } \\
\text { computing infrastructure where third-party software } \\
\text { solutions can then be applied in smart energy systems. }\end{array}$} \\
\hline Fog computing & $\begin{array}{l}\text { Fog computing represents the future computing } \\
\text { infrastructures that have at least the same potential } \\
\text { to revolutionize the software development than }\end{array}$ & \\
\hline & Cloud computın & $\begin{array}{l}\text { - Fog computing opens new possibilities for more } \\
\text { real-time applications that are critical for many energy } \\
\text { systems. }\end{array}$ \\
\hline & & $\begin{array}{l}\text { - Flexible and dynamic computing environment will } \\
\text { make the smart energy systems more self-adaptive. }\end{array}$ \\
\hline & & $\begin{array}{l}\text { - Fog computing enables new possibilities of third-party } \\
\text { companies to execute their software in smart grid } \\
\text { environment. }\end{array}$ \\
\hline & & $\begin{array}{l}\text { - From computing perspective, Fog computing can be } \\
\text { seen as basis for the modernization of the electricity } \\
\text { networks. }\end{array}$ \\
\hline \multirow[t]{4}{*}{ Human data model } & $\begin{array}{l}\text { (PF1) From raw data to programmable abstractions } \\
\text { with human data model }\end{array}$ & $\begin{array}{l}\text { - Human data model allows new types of multi-directional } \\
\text { connections and digital services to be integrated as part } \\
\text { of future energy systems. }\end{array}$ \\
\hline & & $\begin{array}{l}\text { - Together with the human data model and its high-level } \\
\text { sensations (based on the DIKW-pyramid), software following } \\
\text { the loP manifesto's principles could truly help the end-users } \\
\text { (customers) to contribute and help them build and customize } \\
\text { their own energy consumption. }\end{array}$ \\
\hline & & $\begin{array}{l}\text { - Human data model is our solution for applying PCS } \\
\text { computing to smart grids. }\end{array}$ \\
\hline & & $\begin{array}{l}\text { - Human data model enables refining data coming from } \\
\text { multi-modal sources so that it can be used in the smart } \\
\text { energy system's software (i.e., HDM enables tracking human } \\
\text { behavior). }\end{array}$ \\
\hline \multirow[t]{9}{*}{ Internet of People } & $\begin{array}{l}\text { Internet of People principles for more human-centric } \\
\text { interactions with the loT }\end{array}$ & $\begin{array}{l}\text { - Software based on the loP manifesto principles will help } \\
\text { making the future electricity systems truly smart. }\end{array}$ \\
\hline & $\begin{array}{l}\text { (PF2) Personalized, proactive temperature adjustment } \\
\text { based on the preferences of the people }\end{array}$ & $\begin{array}{l}\text { - Human data model enables implementing software that } \\
\text { follows loP manifesto principles to be integrated with smart grids. }\end{array}$ \\
\hline & $\begin{array}{l}\text { (PF3) Proactively selling energy for the local } \\
\text { community }\end{array}$ & $\begin{array}{l}\text { - Human data model will enable the prosumer's solar and wind } \\
\text { power system to predict the prosumers and customers behavior. }\end{array}$ \\
\hline & (PF4) Collective commuting with electric cars & $\begin{array}{l}\text { - Smart grids flavored with new software capabilities can be seen } \\
\text { as key enabling technology towards peer-to-peer energy economy. }\end{array}$ \\
\hline & & $\begin{array}{l}\text { - With the new technical devices and software systems, the user } \\
\text { behavior is possible to observe and possibly even to predict to } \\
\text { some point for energy saving purposes. }\end{array}$ \\
\hline & & $\begin{array}{l}\text { - loP-based software solutions will help also the energy systems } \\
\text { to serve the users in more personalized ways. }\end{array}$ \\
\hline & & $\begin{array}{l}\text { - Proactive software will have the possibility to affect the end-user } \\
\text { energy consumption. }\end{array}$ \\
\hline & & $\begin{array}{l}\text { - Prosumers contribute with their data to help balancing the } \\
\text { smart grids' capacity. }\end{array}$ \\
\hline & & - The new software-based solutions will help saving energy. \\
\hline
\end{tabular}

\section{Software competencies in smart grids}

Based on our exploration of the current software needs in smart grids and their future development trends and consequent roadmaps, we can suggest future-oriented software competence designation frames. Here, we can again lean on the SGAM reference framework to tabularize the software competencies with respect to current smart grid main concepts and categories.

Table 6 presents that in three sections. The conceptual domains are the widest overall concepts in modeling smart grids. The interoperability and the cross-cutting issues are then particularly significant categories due to 
Table 6 Basic software competencies

\begin{tabular}{|c|c|}
\hline Areas [3] & Software competencies \\
\hline \multicolumn{2}{|l|}{ Conceptual domains } \\
\hline Markets & - IS design \\
\hline Energy services & $\begin{array}{l}\text { - Server software, databases, IT/IS interfaces, } \\
\text { cloud }\end{array}$ \\
\hline \multirow[t]{3}{*}{ Operations } & $\begin{array}{l}\text { - Process automation systems, remote data } \\
\text { acquisition and processing (control systems) }\end{array}$ \\
\hline & $\begin{array}{l}\text {-Workstation software, databases, information } \\
\text { processing (distributed systems) }\end{array}$ \\
\hline & $\begin{array}{l}\text { - Data processing, communication protocols } \\
\text { (real-time systems) }\end{array}$ \\
\hline Grid users & $\begin{array}{l}\text { - Intelligent electrical devices (IED) design } \\
\text { (embedded software) }\end{array}$ \\
\hline \multicolumn{2}{|l|}{ Interoperability } \\
\hline Organizational & - IS design (business process engineering) \\
\hline Informational & - Service design, data/information modeling \\
\hline Technical & - Networking, communications \\
\hline \multicolumn{2}{|l|}{ Cross-cutting issues } \\
\hline \multirow{2}{*}{$\begin{array}{l}\text { Shared meaning of } \\
\text { content }\end{array}$} & - Semantics \\
\hline & - Datahubs \\
\hline Resource identification & - APIS \\
\hline $\begin{array}{l}\text { Time synchronization } \\
\text { and sequencing }\end{array}$ & - Reactive and responsive systems design \\
\hline \multirow[t]{2}{*}{ Security and privacy } & - Cyber-security engineering and monitoring \\
\hline & - Data/information management \\
\hline Logging and auditing & $\cdot$ DMS \\
\hline $\begin{array}{l}\text { Transaction and state } \\
\text { management }\end{array}$ & - Platforms \\
\hline \multirow[t]{2}{*}{ System preservation } & - Resilience \\
\hline & - Risk management \\
\hline \multirow{3}{*}{$\begin{array}{l}\text { Performance/ } \\
\text { reliability/scalability }\end{array}$} & - Architecture design \\
\hline & - Performance engineering \\
\hline & - CPS design \\
\hline $\begin{array}{l}\text { Discovery and } \\
\text { configuration }\end{array}$ & - Brokering \\
\hline \multirow[t]{2}{*}{ System evolution } & - Systems design \\
\hline & - Configuration management \\
\hline
\end{tabular}

their overarching, systemic nature that is even radically different from the traditional electricity systems. Software plays a major role in them.

Notably, we assume these basic competencies to be necessary elements in the paths toward our vision of future "software houses" in electricity systems. While many of them may already be partially present, particularly incumbent non-software organizations (actors) should realize their relevant needs and possible gaps.

In addition, there is a wide spectrum of specific software competencies necessary in the different function groups of smart grids. These range from for instance substation automation to smart load and prosumer management with automated consumption measurements (AMI). Furthermore, there could be new intersystem software-related competence needs. For example, the incorporation of weather forecast information for wind and solar energy source management may require certain information management and processing knowledge.

Furthermore, following the latest software research advances discussed above (Table 5), we can identify advanced future software competencies required to utilize such new software technology. Table 7 presents such.

\section{Future energy software house capabilities}

In our view, organizational capabilities of future "software houses" build on their software competencies. Tables 6 and 7 tabulate such key competencies. Based on that comprehension, we can in a similar vein distinguish future key capabilities for different (current) organizations in electricity systems.

The primary organizations (actors) in current smart grids are involved with the electricity generation, transmission (TSO), distribution (DSO), retail, and consumption. Like with the software competence, we do not intend to compile here exhaustive capability inventories for each of them, though.

Since DSOs are central actors in the grids, we reflect them as prime cases of future "software houses." Table 8 presents their key software capabilities tabulated according to the main functionalities. Here, we use the EEGI roadmap as the reference frame [21]. The reasoning of Table 8 is that when the necessary software competencies (Tables 6 and 7) are in place, the organization is enabled to master the software capabilities which are

Table 7 Advanced software competencies

\begin{tabular}{|c|c|}
\hline Areas & Software competencies \\
\hline \multirow[t]{5}{*}{ Fog computing } & - New type of computing infrastructure \\
\hline & - Local computations \\
\hline & - Third party applications \\
\hline & - QoS \\
\hline & - Functional safety \\
\hline \multirow[t]{3}{*}{$\begin{array}{l}\text { Cyber-physical-social } \\
\text { computing }\end{array}$} & $\begin{array}{l}\text { - Combining the virtual, the physical, and } \\
\text { the social worlds }\end{array}$ \\
\hline & - Multi-dimensional interactions \\
\hline & - Data-information-knowledge-wisdom \\
\hline \multirow[t]{3}{*}{ Internet of People } & $\begin{array}{l}\text { - Design guidelines for interactions in human- } \\
\text { centered loT }\end{array}$ \\
\hline & - Data on the user's possession \\
\hline & - Virtual representative (a.k.a. Virtual twin) \\
\hline
\end{tabular}


Table 8 Future DSO software capabilities

\begin{tabular}{|c|c|}
\hline Functionalities (DSO) [21] & Software capabilities \\
\hline \multirow{2}{*}{$\begin{array}{l}\text { Integration of smart } \\
\text { customers }\end{array}$} & - Cyber-security, safety \\
\hline & • "Internet of People" \\
\hline \multirow[t]{2}{*}{$\begin{array}{l}\text { Integration of DER and } \\
\text { new uses }\end{array}$} & $\begin{array}{l}\text { - Large-scale cross-functional } \\
\text { networking, distribution }\end{array}$ \\
\hline & $\begin{array}{l}\text { - More accurate and real-time } \\
\text { information on capacity of storage }\end{array}$ \\
\hline \multirow[t]{3}{*}{ Network operations } & $\begin{array}{l}\text { - Multiple levels of (dynamic, real-time) } \\
\text { controls }\end{array}$ \\
\hline & $\begin{array}{l}\text { - More accurate and real-time information } \\
\text { on electricity usage }\end{array}$ \\
\hline & $\begin{array}{l}\text { - Two-way interaction and information } \\
\text { exchange }\end{array}$ \\
\hline $\begin{array}{l}\text { Network planning and } \\
\text { asset management }\end{array}$ & $\begin{array}{l}\text { - Software-intensive systems engineering, } \\
\text { management and interoperability }\end{array}$ \\
\hline \multirow[t]{2}{*}{ Market design } & - New data sources and exchanges \\
\hline & $\begin{array}{l}\text { - Data on user's possession and then } \\
\text { provided for services }\end{array}$ \\
\hline
\end{tabular}

required to develop and perform the software-intensive functionalities in future smart grids.

An illustrative real-life instance of new digital, software-intensive smart grid services is real-time information about distribution network disruptions to customers with end-user accessible websites and mobile applications [24]. For example in Finland, many DSOs provide such information services for their customers and in addition to national aggregation. ${ }^{6}$ The development and operations of such software system services require many different software elements, possibly such as (SGAM zones):

- Process: power system equipment software to sense the physical power flows

- Field: IED software to capture the data

- Station: distribution system element software to collect and communicate the data

- Operation: DMS and supervisory control and data acquisition (SCADA) systems software to acquire and analyze the information

- Enterprise: customer interface service software to provide the resulting user outputs (possibly with external GIS data sources)

- Market: IS software to provide the information to the inter-enterprise service provider

Moreover, in order to build such a system service, it is not enough to have all the different software components in place. The end-to-end system architecture has to be designed (e.g., the interoperability between the different system layers). The different software parts must then be developed by some "software houses" which have the required software competencies, and the entire software system must be integrated. In practice, some parts of the required software functionalities may already exist for instance in the distribution automation systems. Overall, multidisciplinary software systems engineering competencies are needed to master all those different software elements in each subsystem of the entire electricity system architecture.

\section{Discussion}

Modern electricity systems smart grids can in principle be viewed as power systems coupled with information systems (ICT). Considering them from the software (CS) perspective opens up significant future opportunities but also reveals fundamental complicating issues. As a matter of fact, that is one of our discoveries for the software futures research.

\section{Implications}

Software (ICT) is widely recognized as a key enabling technology for smart grids. This has impacts in two ways (c.f., Fig. 1). It is foundational to realize what is enabled and how with and by software. There are also noticeable pictures of undesirable futures and possible scenario paths leading towards them.

First, future electricity system developments bring new requirements for smart grid technical implementations. That in turn introduces new needs for software realizations. Some of them could be solvable with the current CS knowledge while some problems may really be open software research questions. Moreover, certain software realization issues may be well-defined in theory but require considerable software engineering efforts (e.g., system integration of legacy components). That is, we are interested in whether there could be significant opportunities for more software advances, what the current obstacles are, if there are software commonalities (e.g., in different electricity system components), and-in conclusion-identifying new software research areas, open research questions, and theoretical knowledge gaps.

One fundamental property with possibly significant software-related impacts is the inherent and in currently foreseeable future energy systems scenario paths increasing complexity of electricity systems [19]. This is caused by such factors as the increasing share of intermittent DERs (e.g., wind) and their different nature compared to traditional bulk-generation [20]. They may require for instance new software-based measurement solutions for the grid operations. Furthermore, modeling and planning such complex networks need more powerful tools which may also bring new software research needs. In all, it is crucial to understand whether and where the level of complexity is really beyond the current capabilities. 
Secondly, the other way around, future software research may introduce new approaches and solution alternatives to develop smart grids in new ways. For instance, existing hardware-based system components may become more software-based and implemented with standard general-purpose hardware equipment (e.g., IoT nodes).

Comparing and contrasting to extant literature and related developments, we recognize that in the smart grid domain there are many kinds of works which are indirectly linked to considering ICT and software as enabling technologies. There are for instance certain maturity models for smart grids [31, 52]. Our intention here is not to propose any particular maturity development or assessment model. However, what we do advocate and encourage is that each electricity system organization should ponder their role as a "software house" in the smart grid systems and even ecosystems. While the primary technology is still about power systems discipline, the increasing role of software makes it more and more important for each smart grid organization to realize their current and future, possibly even critical software competencies and capabilities. While they are enabling with respect to the primary power technology, lack of them may become disablers and hindrances to fully realize future smart grids taken full advantage of the primary technology developments.

Overall, from the CS perspective, we can see that there are more computing elements in electricity systems. They make it possible to get more (real-time) data, and they enable flexible and intelligent ("smart") functions and services. Furthermore, cloud and high-performing widely interconnected communications enable new and improved solutions by software and integration to other than electricity systems.

In total, the electricity systems are increasingly under "softafication." It follows that the energy industry and business sector may be facing new entrants, which are by nature capable with software competencies from different sectors such as ICT companies [5]. For unprepared incumbent energy companies, this may cause even radical disruptions but by consciously and systematically realizing the probable future developments and the role of software in there like we have suggested in this paper, they may be able to stay competitive.

\section{Limitations}

By and large, smart grids involve multiple different domains of knowledge and disciplines. Our core software competence is based on CS. We acknowledge the principal fact that power systems engineering is a different field of expertise. Also the human-oriented aspects of electricity systems such as consumer behavior are closer to other academic disciplines, particularly social sciences. However, we maintain that since software is more inherent across the smart grids both in the power system and the information management parts including the digital customer services, our software-oriented standpoint is in general relevant. This is our worldview reflected in Fig. 1.

A practical constraint is that our investigation is based on publicly available reference material only. For instance, no industrial utility company internal data has been accessible. Nevertheless, we believe that, by using a rich variety of the reference material reflecting not only traditional CS and software engineering literature but more importantly cross-disciplinary energy systems research and development, our work is in general reasonably valid. Interestingly enough, notably, we are also ourselves individual customers and end-users of (smart grid) electricity systems with for example online access to our private household electricity consumption data based on AMR.

\section{Future work}

Interestingly enough, since future electricity energy systems research is multidisciplinary and covers a wide range of research topics, it is foundational to recognize overarching futures research avenues. However, even limiting to the core software focus leads to a gamut of possible research questions. A more constructive and reasonable way would be to first capture systematically key pictures of smart grid futures and their scenario paths informed by the energy systems knowledge and expertise, and then analyze them with respect to the practical and theoretical implications with respect to software. In our view, the Futures Map frame is an appropriate means for doing that [2]. That is actually what we have provisionally started doing in this paper, but future work would proceed cooperatively with energy systems experts. In this paper, we have identified some pictures of the software-enabled electricity system smart grid futures and the connecting software competence-based scenario paths. These are intended to contribute as preliminary inputs for the comprehensive futures mapping work like depicted in Fig. 7.

In the future, for the systematic constructing of the comprehensive Futures Map, we pursue to conduct empirical investigations of the pictures of futures presented in this paper with DSO companies and electricity system equipment vendors considering their present standings and future views as "software houses." In doing so, we may also utilize our prior, domain-independent views of future software organizations [1]. Notably, for a comprehensive Futures Map, it is important to identify also all relevant undesirable futures. We are especially interested in critical software-related pictures and their competence-related 
Sect. Future energy systems and software

Sect. Computer science perspective: software systems and data

Sect. Future software-related dependencies and opportunities

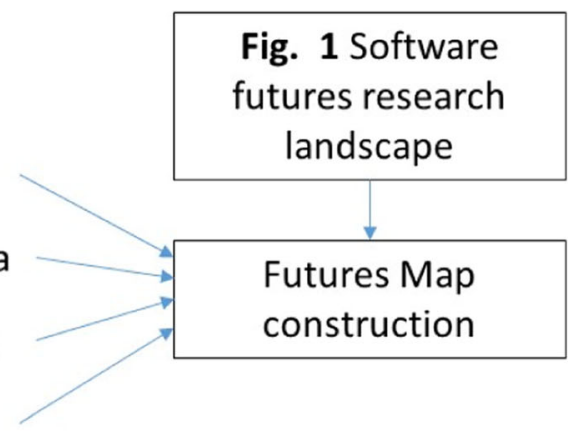

Sect. Future software competencies and capabilities

- Vision

- Pictures of possible, probable and preferable futures

- Potentially important scenario paths

- Potentially futures-relavant past and present facts

- Potential emergent software-based pictures of futures and scenario paths

Fig. 7 Futures Map construction scheme

scenario paths-e.g., electricity distribution outages caused by lack of real-time software design competences or hackers able to access confidential energy data because of weak IT systems security measures. We shall also look for cooperation with the related future energy systems research. That would strengthen the quality of our futures research work and the validity of the aspired Futures Map [35].

In such collaborative construction process of the Futures Map, we propose to contemplate the following guiding questions for each picture of future and scenario path:

1. What are the necessary key software competencies and capabilities? How to develop or acquire them?

2. What are the underlying software (CS) research questions? What are the knowledge gaps?

The software competence and capability tabulations compiled in this paper are expected to serve the former question. For the latter one, focusing on software research and our computer science core competence, the principal idea is to realize what critical software-related problems (CS/software engineering/IT) there exist. This should be realized in a dualistic way:

1. What critical power system problems are already known (and possibly solved) software problems?

2. What minor power system problems are significant software problems (possibly even open research questions)?
It should be noted that for some of the critical power system issues in smart grids, the technology (including software) may already be currently available or expected to be available in the near future [28]. However, conversely, for certain power system problem areas, it may be so that the existing technologies or traditional engineering methods are inadequate and not feasible for future, larger, and more complex smart grids [29]. It is crucial to be able to recognize them in advance, and this is what we have attempted to support with this paper.

\section{Conclusions}

In this paper, we have discerned future smart energy systems focusing on electricity smart grids with respect to software. In general, the role of software (ICT) as a key enabling technology for smart grids has already been widely recognized. However, it is necessary to systematize that further in order to be able to develop and operate the future, increasingly software-intensive and more complex systems-of-systems in sustainable and reliable ways. Such comprehensive understanding serves both the future "software houses" in the smart grid domain and the related software (computer science) research. Futures research-particularly the Futures Map approach-can systematically support that.

Informed by energy systems research literature and other relevant sources coupled with our computer science knowledge, we have identified and examined certain trends, scenario paths, and pictures of futures of future software-intensive electricity systems. Consequently, in our vision, new software competencies and 
software-based capabilities will be required in all future smart energy system houses. In this paper, we have logically recognized and reasoned such key competencies based on computer science/software engineering knowledge and software technology roadmaps. These are aimed to be inputs for further Futures Map work serving both energy systems customers (decision-makers) and researchers.

Like depicted in Fig. 1, electricity system transformations are multi-level and multidimensional. Multidisciplinary research and developments are thus needed. For the software future research in the future energy systems, it requires cooperation not only with the principal energy technology research but also with the end-user and customer perspectives. The other way around, we encourage those related disciplines to collaborate with computer scientists to discover the modern software technology opportunities on the one hand, and to fetch software research with relevant open research problems on the other hand.

\section{Endnotes}

${ }^{1}$ https://ec.europa.eu/energy/en/topics/energy-strategy-and-energy-union/2050-energy-strategy

${ }^{2}$ https://aws.amazon.com/lambda/

${ }^{3}$ https://cloud.google.com/functions/

${ }^{4}$ https://azure.microsoft.com/en-us/services/functions/

${ }^{5}$ https://github.com/HumanDataModel

${ }^{6}$ http://www.sähkökatkokartta.fi/\#/nyt

\begin{abstract}
Abbreviations
AMI: Advanced metering infrastructure; AMR: Automated meter reading; API: Application program interface; CPS: Cyber-physical system; CPSS: Cyberphysical-social system; CS: Computer science; DER: Distributed energy resource; DIKW: Data-information-knowledge-wisdom; DMS: Distribution management system; DR: Demand response; DSO: Distribution system operator; EEGI: European Electricity Grid Initiative; EV: Electrical vehicle; HDM: Human data model; ICT: Information and communication technology; IED: Intelligent electrical devices; IOP: Internet of People; IOT: Internet of Things; ISD: Information systems development; IT: Information technology; KET: Key enabling technology; MLP: Multi-level perspective; OT: Operational technology; PCS: Physical-cyber-social; PeaaS: People as a service; SCADA: Supervisory control and data acquisition; SGAM: Smart Grid Reference Architecture Model; SoS: System-of-systems; TSO: Transmission system operator; VPP: Virtual power plant
\end{abstract}

\section{Acknowledgements}

Not applicable.

\section{Funding}

Not applicable.

\section{Availability of data and materials}

Not applicable.

\section{Authors' contributions}

The manuscript has been compiled jointly by PK and NM following the associated conference abstract (https://

futuresconference2018.files.wordpress.com/2018/06/energizing-boa-web.pdf) and the related conference presentation presented by the authors together. PK authored the body of the main sections while NM's key contribution was the subsection "Future software-related opportunities". All authors read and approved the final mansucript.

\section{Competing interests}

The authors declare that they have no competing interests.

\section{Publisher's Note}

Springer Nature remains neutral with regard to jurisdictional claims in published maps and institutional affiliations.

Received: 1 August 2018 Accepted: 21 December 2018

Published online: 19 January 2019

\section{References}

1. Kettunen P, Laanti M (2017) Future software organizations-agile goals and roles. Eur J Futur Res 5:16

2. Kuusi O, Cuhls K, Steinmüller K (2015) The futures map and its quality criteria. Eur J Futur Res 3:22

3. CEN-CENELEC-ETSI Smart Grid Coordination Group (2012) Smart grid reference architecture. CEN-CENELEC-ETSI SG-CG/M490/C_

4. International Energy Agency and International Renewable Energy Agency (2017) Perspectives for the energy transition: investment needs for a lowcarbon energy system. OECD/IEA and IRENA

5. Geels FW (2018) Disruption and low-carbon system transformation: progress and new challenges in socio-technical transitions research and the multilevel perspective. Energy Res Soc Sci 37:224-231

6. BCDC Energy. http://www.bcdcenergia.fi/en/. Accessed 30 July 2018

7. Mai T, Steinberg D, Logan J, Bielen D, Eurek K, McMillan C (2018) An electrified future. IEEE Power Energ Mag 16(4):34-47

8. World Economic Forum (2017) The future of electricity: new technologies transforming the grid edge, REF 030317. World Economic Forum, Cologny/ Geneva

9. Giordano V, Fulli G (2012) A business case for smart grid technologies: a systemic perspective. Energy Policy 40:252-259

10. Midttun A, Piccini PB (2017) Facing the climate change and digital challenge: European energy industry from to crisis and transformation. Energy Policy 108:330-343

11. Ministry of Economic Affairs and Employment (2016) Finnish smart grid vision. https://tem.fi/documents/1410877/3481825/Smart+grid+vision +30102016+final_EN.pdf/479bdd14-2794-4cea-8f77-b9f5dc2d8a2d. Accessed 30 July 2018

12. ENTSO-E, RD\&l Roadmap 2017-2026. https:/www.entsoe.eu/publications/ research-and-development/\#rdi-roadmap-2017-2026. Accessed 30 July 2018

13. Baran ME, Carpenter PP, Borbye L (2014) A new professional science master program for electric power systems engineering. IEEE Trans Power Syst 29(4):1903-1910

14. Eltom AH et al (2018) Smart distribution course for 21st century power sector workforce. IEEE Transactions on Power Systems, vol. 33, Issue: 5, pp. 5639-5647

15. Varadan S (2012) Today's workforce in tomorrow's smart grid: bridging the growing gaps. In: Proceedings IEEE Power and Energy Society General Meeting. IEEE, San Diego

16. Ahlstrom M (2017) New skills needed: structural transformation in the electricity industry. IEEE Power Energ Mag 15(6):112,116

17. Voas J, Laplante P (2017) Curriculum considerations for the internet of things. IEEE Comput 50(1):72-75

18. Heinonen S, Karjalainen J, Ruotsalainen J, Steinmüller K (2017) Surprise as the new normal_-implications for energy security. Eur J Futur Res 5:12

19. Bale CSE, Varga L, Foxon TJ (2015) Energy and complexity: new ways forward. Appl Energy 138:150-159

20. Panula-Ontto J et al (2018) Cross-impact analysis of Finnish electricity system with increased renewables: long-run energy policy challenges in balancing supply and consumption. Energy Policy 118:504-513

21. Mallet P, Granstrom P-O, Hallberg P, Lorenz G, Mandatova P (2014) Power to the people!: European perspectives on the future of electric distribution. IEEE Power Energ Mag 12(2):51-64

22. Parkkinen J, Järventausta P (2012) SGEM Questionnaire for Smart Grids RoadMap. http://sgemfinalreport.fi/files/SGEM_ Smart\%20Grids\%20Roadmap\%200uestionary\%20-\%201-2-2012.pdf. Accessed 30 July 2018 
23. Kakran S, Chanana S (2018) Smart operations of smart grids integrated with distributed generation: a review. Renew Sust Energ Rev 81:524-535

24. EURELECTRIC (2017) Transformational perspective: data as critical asset for the energy transition. D/2017/12.105/56. Union of the Electricity Industry, Brussels

25. Ahonen T, Marttila T, Dukeov I, Jalas M (2017) Understanding smart energy transition: insights to the future energy technologies and their market disruption in Finland. In: Saarimaa R, Wilenius M (eds) Proceedings of the conference "futures of a complex world". Finland Futures Research Centre, Turku, pp 197-206

26. Schöllhorn D, Iglhaut D, Waldburger M, Wissner M (2017) Future ICTinfrastructure for smart grids. In: Derksen C, Weber C (eds) SmartER Europe 2016/2017, IFIP AICT 495, pp 43-55

27. Bayindir R, Colak I, Fulli G, Demirtas K (2016) Smart grid technologies and applications. Renew Sust Energ Rev 66:499-516

28. Colak I, Sagiroglu S, Fulli G, Yesilbudak M, Covrig CF (2016) A survey on the critical issues in smart grid technologies. Renew Sust Energ Rev 54:396-405

29. Yu X, Xue Y (2016) Smart grids: a cyber-physical systems perspective. Proc IEEE 104(5):1058-1070

30. Khaitan SK, McCalley JD (2015) Design techniques and applications of cyberphysical systems: a survey. IEEE Syst J 9(2):350-365

31. U.S. Department of Energy, Electricity Subsector Cybersecurity Capability Maturity Model (ES-C2M2). https://www.energy.gov/oe/cybersecuritycapability-maturity-model-c2m2-program/electricity-subsector-cybersecurity. Accessed 30 July 2018

32. He H, Yan J (2016) Cyber-physical attacks and defences in the smart grid: a survey. IET Cyber-Phys Syst Theory Appl 1(1):13-27

33. Kshetri N, Voas J (2017) Hacking power grids: a current problem. IEEE Computer 50(12):91-95

34. Pfenninger S, DeCarolis J, Hirth L, Quoilin S, Staffell I (2017) The importance of open data and software: is energy research lagging behind? Energy Policy 101:211-215

35. Kuusi O, Cuhls K, Steinmüller K (2015) Quality criteria for scientific futures research. Futura 34(1):60-77

36. Mäkitalo N, Ometov A, Kannisto J, Andreev S, Koucheryavy Y, Mikkonen T (2017) Safe, secure executions at the network edge: coordinating cloud, edge, and fog computing. IEEE Softw 35(1):30-37

37. Mäkitalo N, Nocera F, Mongiello M, Bistarelli S (2018) Architecting the web of things for the fog computing era. IET Softw. https://doi.org/10. 1049/iet-sen.2017.0350

38. Kalske M, Mäkitalo N, Mikkonen T (2017) Challenges when moving from monolith to microservice architecture. In: Garrigós I, Wimmer M (eds) International conference on web engineering ICWE 2017. Lecture notes in computer science, vol 10544. Springer, Cham, pp 32-47

39. Lehvä J, Mäkitalo N, Mikkonen T (2017) Case study: building a serverless messenger chatbot. In: Garrigós I, Wimmer M (eds) International conference on web engineering ICWE 2017. Lecture notes in computer science, vol 10544. Springer, Cham, pp 75-86

40. Eivy A (2017) Be wary of the economics of "Serverless" cloud computing IEEE Cloud Comput 4(2):6-12

41. Sheth A, Anantharam P, Henson C (2013) Physical-cyber-social computing: an early 21st century approach. IEEE Intell Syst 28(1):78-82

42. Zeng J, Yang LT, Lin M, Ning H, Ma J (2016) A survey: Cyber-physical-social systems and their system-level design methodology. Futur Gener Comput Syst. ISSN 0167-739X. https://doi.org/10.1016/j.future.2016.06.034.

43. Liu Z, Yang DS, Wen D, Zhang WM, Mao W (2011) Cyber-physical-social systems for command and control. IEEE Intell Syst 26(4):92-96

44. Wang FY (2010) The emergence of intelligent enterprises: from CPS to CPSS IEEE Intell Syst 25(4):85-88

45. Sheth A (2010) Computing for human experience: semantics-empowered sensors, services, and social computing on the ubiquitous web. IEEE Internet Comput 14(1):88-91

46. Sowe SK, Zettsu K, Simmon E, de Vaulx F, Bojanova I (2016) Cyber-physical human systems: putting people in the loop. IT Prof 18(1):10-13

47. Miranda J, Mäkitalo N, Garcia-Alonso J, Berrocal J, Mikkonen T, Canal C, Murillo JM (2015) From the internet of things to the internet of people. IEEE Internet Comput 19(2):40-47

48. Guillen J, Miranda J, Berrocal J, Garcia-Alonso J, Murillo JM, Canal C (2014) People as a service: a mobile-centric model for providing collective sociological profiles. IEEE Softw 31(2):48-53
49. Mäkitalo N et al (2012) Social devices: collaborative co-located interactions in a mobile cloud. In: Proceedings of the 11th international conference on mobile and ubiquitous multimedia MUM '12. ACM, UIm

50. Heiskanen E, Matschoss KJ (2016) Experiments for identifying necessary and missing competences for a smart and sustainable energy system. In: European conferences on the human dimensions of global environmental change. Freie Universität Berlin, Berlin

51. Heiskanen E, Matschoss K (2016) Consumers as innovators in the electricity sector? Consumer perceptions on smart grid services. Int J Consum Stud 40(6):665-674

52. CMU/SEl (2011) Smart grid maturity model (SGMM). Report CMU/SEl-2011-TR-025

53. Brandt T (2016) IT solutions for the smart grid. Dissertation, University of Freiburg, Germany. Springer Fachmedien, Wiesbaden

54. United Nations, Transforming our world: the 2030 Agenda for Sustainable Development. https://sustainabledevelopment.un.org/post2015/ transformingourworld. Accessed 30 July 2018

55. European Commission, 2030 Energy Strategy. https://ec.europa.eu/energy/ en/topics/energy-strategy-and-energy-union/2030-energy-strategy. Accessed 30 July 2018

56. Lappeenranta University of Technology (2017) Haja-asutusalueiden sähköverkko ja sähköasiakas 2030 (in Finnish). https://energia.fi/files/1463/ Haja-asutusalueiden_sahkoverkko_ja_sahkoasiakas_2030_Arto_Gylen.pdf. Accessed 30 July 2018

57. Järventausta $P$, Verho $P$, Partanen J, Kronman D (2011) Finnish smart grids - a migration from version one to the next generation. In: 21st international conference on electricity distribution. CIRED, Frankfurt

58. Spinellis D (2016) Research priorities in the area of software technologies. Report prepared for the EU DG communications networks, content and technology - E2 PO 30-CE-0751856/00-91, European Commission

59. Strengers $Y$ (2013) Smart energy technologies in everyday life. Palgrave Macmillan, England

\section{Submit your manuscript to a SpringerOpen ${ }^{\circ}$ journal and benefit from:}

- Convenient online submission

- Rigorous peer review

- Open access: articles freely available online

- High visibility within the field

- Retaining the copyright to your article

Submit your next manuscript at $>$ springeropen.com 